Universidade de São Paulo

Instituto de Física

\title{
Estudo do modelo de Bose- Hubbard usando o algoritmo Worm
}

\author{
Karine Piacentini Coelho da Costa \\ Dissertação apresentada ao \\ Instituto de Física da Uni- \\ versidade de São Paulo \\ para obtenção do título de \\ mestre em Ciências.
}

Orientador:

Prof. Dr. Arnaldo Gammal (IFUSP)

Banca examinadora:

Prof. Dr. Arnaldo Gammal (IFUSP)

Prof. Dr. Marcelo Martinelli (IFUSP)

Prof. Dr. Marcelo Takeshi Yamashita (IFT/UNESP)

São Paulo

2011 

À meu pai, quem me introduziu à ciência. 



\section{Sumário}

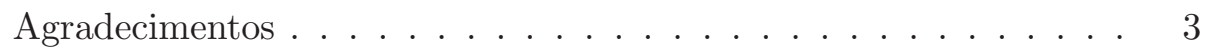

Resumo .......................... 5

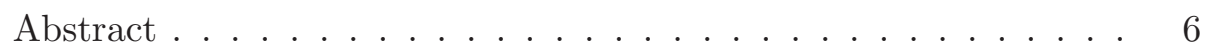

Lista de abreviações . . . . . . . . . . . . . . 7

1 Introdução $\quad 9$

2 O Modelo de Bose-Hubbard 13

2.1 Gases bosônicos aprisionados em redes óticas . . . . . . . . 13

2.1 .1 Interações . . . . . . . . . . . . . . . . . . . . 14

2.1.2 Redes óticas . . . . . . . . . . . . . . . . . . 15

2.2 Considerações a respeito de potenciais periódicos . . . . . 16

2.3 A hamiltoniana de Bose-Hubbard . . . . . . . . . . . 20

3 Um estudo preliminar do modelo $\quad 24$

3.1 A transição de Mott . . . . . . . . . . . . . . . . . 24

3.2 Uma aproximação de campo médio . . . . . . . . . . . . . 28

3.3 Diagrama de fases I . . . . . . . . . . . . . . . . . . . . . . 29

4 Monte Carlo Quântico 35

4.1 O método de Monte Carlo clássico . . . . . . . . . . . . 35

4.2 Monte Carlo de integral de caminho . . . . . . . . . 36

4.2.1 Integral de caminho para o modelo de Bose-Hubbard . 41

4.3 O algoritmo Worm . . . . . . . . . . . . . . . 44

4.3.1 Criação e destruição do verme . . . . . . . . . . 46

4.3.2 Movimentação temporal . . . . . . . . . . . . . . 47

4.3 .3 Movimentação espacial . . . . . . . . . . . . . . . 47

4.3.4 Considerações . . . . . . . . . . . . . . . . . . . 52 
5 Resultados utilizando o Worm 54

5.1 Diagrama de fases II: ajustes e refinamentos . . . . . . . . . 54

5.1 .1 Critérios . . . . . . . . . . . . 55

5.1 .2 Estudo da temperatura . . . . . . . . . . 57

5.1 .3 Estudo da grade . . . . . . . . . . . . . . . . 60

5.2 Comparação qualitativa com a teoria de campo médio . . . . 62

5.3 Encontrando o ponto crítico . . . . . . . . . . . . . . . 64

5.3.1 Comparação com a literatura . . . . . . . . . . 66

5.3.2 Comparação com os experimentos atuais . . . . . . 66

6 Conclusão $\quad 70$

$\begin{array}{ll}\text { A Segunda quantização } & 73\end{array}$

$\begin{array}{ll}\text { Referências } & 76\end{array}$ 


\section{Agradecimentos}

Vim com muitas esperanças e expectativas a São Paulo, essa dissertação é fruto de muitos esforços e se cheguei perto do que eu esperava realizar, muito tenho a agradecer às pessoas que conheci aqui e as que mesmo à distância me apoiaram. É muito difícil agradecer propriamente a todos, fazer parte da vida de alguém é muito mais do que a simples existência e casualidade e por isso dedico algumas poucas palavras que minimamente representam a minha gratidão àqueles que participaram da minha vida nesse periodo.

Primeiramente queria agradecer ao professor Arnaldo Gammal pela orientação, atenção e paciência. Tive sorte por encontrar um orientador tão acessivel e preocupado com o futuro de seus alunos. Acredito que o maior papel do orientador seja o de ensinar o orientando a deixar de ser apenas um estudante e se tornar um pesquisador, agradeço por ter me ensinado os primeiros passos.

I would like to thank professor Nikolay Prokof'ev for all the help and attention. For answering all our questions about the Worm algorithm, showing one of the most beautiful aspect of science: collaboration and freedom of ideas.

Por me doarem seu tempo lendo a dissertação, pelas direções e valiosas críticas agradeço a Eder e meu pai Rosvelter. Pelas dicas e ajuda com a apresentação agradeço a Paula e ao Tiago. Em especial, agradeço a Leandro Beviláqua por suas sugestões e atenção na leitura da tese e nos slides da apresentação.

Aos professores que contribuiram para minha formação nessa instituição, João Barata, Silvio Salinas, Celso Lima, Emerson Passos e a Antônio de Toledo Piza, agradeço não só pelo ensinamento mas também pela inspiração.

Agradeço ao meus colegas e amigos de grupo Eder, Eduardo, Hedhio e Leandro Saccoletto pelo suporte, discussões e por terem me acolhido tão bem. 
Aos amigos que me fazem sentir saudades de Florianópolis quando estou em São Paulo...

À todos os amigos que fiz no ensino médio e na graduação que permaneceram em contato, em especial Jeison, Nara, Nathália e Nauana. Também às amizades que se mantêm firmes desde a infância, Amanda, Maíra e Thaïs. É impossivel dizer em poucas palavras o que vocês representam pra mim, têm minhas melhores lembranças da infância e adolescência, eu as guardarei com carinho para sempre em meu coração. Obrigada por todas as conversas, pelos momentos de alegria e tristeza compartilhados e por terem me ensinado o valor da amizade.

... e aos que me fazem sentir saudades de São Paulo quando estou em Florianópolis.

Aos amigos do IFUSP, Antônio, Jorgivan, Nayara, Paula e Tiago, que tornaram essa cidade tão querida e que tanto me inspiraram (aprendi muita física com eles!). Agradeço a Nayara e Pâmella por transformarem junto comigo um apartamento em lar. Também sou muito grata a Guga, Léa e Lani, que me acolheram em São Paulo quando cheguei, fizeram toda a diferença.

A meus pais, Rosvelter e Suilane, agradeço pelo que sou hoje. Por todo amor, dedicação e apoio, e por me fazerem acreditar num mundo melhor. Aos meus irmãos, Chamili, Meline e Igor, de quem muito me orgulho. Obrigada por estarem tão presente na minha formação, por todas as confidências, incentivo e companheirismo.

Mais do que agradecer, quero dedicar a conclusão desta dissertação a Leandro Beviláqua, uma preciosidade que conheci durante o mestrado. Obrigada por todo apoio e ajuda. Se por vezes me faltaram forças para continuar, sempre esteve disposto a me empurrar se fosse preciso. Todas as suas palavras de motivação e seus conselhos me ajudaram no meu amadurecimento profissional. Não me faltam motivos para lhe agradecer, obrigada principalmente por me fazer ser uma pessoa melhor e dar mais significado ao meus dias.

* Pelo apoio financeiro, agradeço ao Conselho Nacional de Desenvolvimento Científico e Tecnológico ( $\mathrm{CNPq})$. 


\section{Resumo}

Nesta dissertação estudaremos sistemas de bósons ultrafrios armadilhados em uma rede ótica quadrada bidimensional sem levar em consideração o confinamento harmônico. A dinâmica desses sistemas é bem descrita pelo modelo de Bose-Hubbard, que prevê uma transição de fase quântica de um superfluido para um isolante de Mott a temperaturas baixas, e pode ser induzida variando a profundidade do potencial da rede ótica. Apresentaremos o diagrama de fases dessa transição construído a partir de uma aproximação de campo médio e também com um cálculo numérico usando um algoritmo de Monte Carlo Quântico, denominado algoritmo Worm. Encontramos o ponto crítico para o primeiro lobo de Mott em ambos os casos, concordando com trabalhos anteriores. 


\begin{abstract}
This work study the two-dimensional ultracold bosonic atoms loaded in a square optical lattice, without harmonic confinement. The dynamics of this system is described by the Bose-Hubbard model, which predicts a quantum phase transition from a superfluid to a Mott-insulator at low temperatures that can be induced by varying the depth of the optical potential. We present here the phase diagram of this transition built from a mean field approach and from a numerical calculation using a Quantum Monte Carlo algorithm, namely the Worm algorithm. We found the critical transition point for the first Mott lobe in both cases, in agreement with the standard literature.
\end{abstract}




\title{
Lista de abreviações
}

\author{
$\mathrm{CBE} \rightarrow$ Condensado de Bose-Einstein \\ $\mathrm{BH} \rightarrow$ Bose-Hubbard \\ $\mathrm{SF} \rightarrow$ Superfluido \\ $\mathrm{MI} \rightarrow$ Isolante de $\operatorname{Mott}^{(*)}$ \\ $\mathrm{CM} \rightarrow$ Campo médio \\ $\mathrm{DF} \rightarrow$ Diagrama de fases \\ $\mathrm{QMC} \rightarrow$ Monte Carlo Quântico ${ }^{(*)}$ \\ $\mathrm{CF} \rightarrow$ Caminho fechado \\ $\mathrm{CF}_{g} \rightarrow$ Caminho aberto (na qual $g$ denota a ligação com a função de \\ Green)
}

(*) Abreviações adotadas como usado na literatura, isto é, referentes ao termo correspondente em inglês. 



\section{Capítulo 1}

\section{Introdução}

O fenômeno da condensação de Bose-Einstein (CBE) teoricamente concebido por S. Bose $(1924)$ e A. Einstein $(1924 ; 1925)$ teve sua primeira realização experimental em 1995 [1]. Quando um gás de bósons é suficientemente resfriado os comprimentos de onda de de Broglie dos átomos são da ordem das distâncias interatômicas e fenômenos quânticos se tornam importantes. Deste modo, os bósons sofrem uma transição de fase passando a formar um CBE, uma nuvem de átomos densa e coerente onde todos os átomos ocupam o mesmo estado quântico [2]. Sua realização abriu muitas possibilidades de pesquisa, conectando a física atômica, a ótica quântica e a matéria condensada.

Avanços experimentais permitiram o aprisionamento de CBE em redes óticas, renovando esta área de pesquisa com novos experimentos. O controle alcançado nesses sistemas nos permite utilizá-los como verdadeiros laboratórios de modo que podemos abordar problemas que ainda estão em aberto na matéria condensada e que são muito difíceis de serem estudados nos materiais convencionais [3]. Em outras palavras, diferentemente do que ocorre em um cristal, por exemplo, que tem uma rede fixa e definida, os parâmetros dessas redes óticas podem ser controlados com facilidade. Por exemplo, o período e a profundidade de cada sítio da rede podem ser alterados modificando, respectivamente, a frequência e a intensidade dos lasers que a formam $[4,5]$. Também, a interação entre as partículas presas à rede pode ser manipulada via ressonância de Feshbach [6].

Recentemente, Greiner et al. [7] tiveram sucesso em demonstrar experimentalmente uma transição de fase que ocorre em uma rede ótica com bósons ultrafrios aprisionados. A partir de uma fase superfluida (SF), na qual os átomos estão deslocalizados, o sistema passa para uma fase em que 
os átomos estão localizados nos sítio da rede, denominada isolante de Mott (MI). Esta transição é um exemplo de uma transição de fase quântica já que classicamente não pode haver nenhuma transição de fase em sistemas à temperatura zero, uma vez que todas as flutuações térmicas estão congeladas [7]. Por outro lado, em sistemas quânticos, devido ao princípio de incerteza de Heisenberg, flutuações estão presentes mesmo à $T=0 \mathrm{~K}$ e podem induzir uma transição de fase no sistema.

Um modo de visualizar a transição SF-MI é pensar na rede ótica como uma bandeja de ovos, em que cada reentrância representa um poço de potencial. Classicamente, os ovos ficam localizados em seus respectivos compartimentos a menos que haja energia suficiente para movê-los (alguém sacudindo a bandeja, por exemplo). Entretanto, se em vez de ovos temos partículas quânticas, um dos graus de liberdade é o tunelamento e portanto há uma probabilidade não nula dessas partículas mudarem de sítio mesmo que não haja energia suficiente para vencer o poço de potencial. A analogia com ovos oferece um outro inconveniente, já que apenas um ovo é permitido por sítio. Nas redes óticas, podemos ter uma ocupação dupla ou tripla, etc. Todavia, se considerarmos interação entre essas partículas, o sistema preferirá uma ocupação individual, pois há uma penalidade energética às ocupações dupla, tripla ou maiores de um sítio. Com isso, fica claro que a transição de fase é caracterizada por uma competição entre a intensidade de tunelamento $(J)$ e a intensidade da interação entre as partículas $(U)$. Se o primeiro for dominante, as partículas tenderão a estar deslocalizadas e o sistema se encontra na fase superfluida. Caso contrário, o sistema se encontrará na fase Mott, já que a penalidade energética pela movimentação de uma partícula entre os sítios será alta e fará com que as partículas tendam a estar isoladas.

O experimento supracitado de Greiner et al. [7] seguiu uma proposta de Jaksch et al. em [8], no qual se sugere que a profundidade do poço altera a intensidade do tunelamento e da interação entre as partículas, de modo que a transição de fase SF-MI pode ser induzida simplesmente por uma variação na profundidade do poço de potencial da rede. No experimento, carregaram um CBE de átomos de ${ }^{87} \mathrm{Rb}$ em uma rede ótica 3D. Desligando as armadilhas confinantes, obtiveram figuras com padrões de interferência que identificam cada fase. Quando o sistema está na fase SF, vemos um padrão de interferência bem definido indicando uma forte coerência do sistema. Ao passar para a fase Mott, esse padrão muda significativamente, desaparecendo numa fase isolante de Mott pura, mostrando que o sistema perdeu a coerência. Mostraram que esta transição é reversível, isto é, a coerência é recuperada quando volta-se à profundidade inicial. Também obtiveram uma estimativa do ponto de transição para o caso 3D. 
Nesta dissertação estamos interessados na descrição teórica da transição SF-MI. Fenômenos envolvendo CBE são geralmente descritos pela equação não-linear denominada de Gross-Pitaevskii $[1,5]$. No entanto ela descreve interações fracas e aproxima a função de onda do condensado por um campo médio. A fase isolante de Mott, por ser um regime fortemente interagente, não pode ser descrita por essa equação [7]. Em 1989, Fisher et al. [9] obtiveram um diagrama de fases da transição SF-MI utilizando o modelo de Hubbard aplicado ao caso bosônico, o chamado modelo de Bose-Hubbard (BH). Este modelo foi proposto no contexto do estado sólido para descrever elétrons interagentes em sólidos e é utilizado para estudar a transição metalisolante de Mott [10, 11]. Em sistemas bosônicos, ele capta os elementos essenciais da transição de interesse descrevendo bem a dinâmica de átomos aprisionados em redes óticas.

Baseados nos trabalhos apresentados em [12, 13], estudaremos o modelo de $\mathrm{BH}$ analiticamente utilizando uma aproximação de campo médio. O desenvolvimento teórico que iremos apresentar trata exatamente a interação e aproxima a energia cinética dos átomos na rede. Obteremos um diagrama de fases da transição que está qualitativamente correto, mas que subestima uma região da fase Mott. Este estudo é importante para entendermos a dinâmica do sistema, mas para uma comparação direta com a experiência, necessitamos de um tratamento mais acurado.

Uma descrição mais adequada para a transição SF-MI pode ser feita por uma análise numérica. Utilizamos o algoritmo Worm, originalmente introduzido para modelos quânticos estatísticos por Prokof'ev, Svistunov e Tupitsyn [14] e depois generalizado para modelos clássicos por Prokof'ev e Svistunov [15]. É um Monte Carlo Quântico (QMC), que no caso simula um problema de muitos corpos passando a tratá-lo em uma dimensão a mais fazendo o uso de integrais de caminho e técnicas de Monte Carlo. Obtemos um diagrama de fases com esse algoritmo.

Para finalizar é interessante listarmos algumas características do algoritmo Worm, dentre elas: (a) não é afetado pelo problema conhecido como critical slowing down, sobre o qual falaremos no capítulo 4; (b) trabalha no ensemble grande canônico; e (c) suas atualizações são todas locais. Entretanto, vale enfatizar que o algoritmo não é adequado para simular a evolução temporal do sistema, sendo restrito ao estado fundamental.

Trataremos o caso mais simples do modelo, com bósons sem spins aprisionados em uma rede quadrada, e não consideraremos interações de longo alcance, nem a influência da armadilha harmônica externa que é utilizada nos experimentos para confinar o condensado. É claro que esses efeitos são importantes para uma descrição mais próxima da realidade, mas o trata- 
mento é mais elaborado e alguns resultados importantes podem ser obtidos com essas simplificações. Além disso, descrevemos apenas o sistema 2D, já que o sistema 1D não apresenta superfluidez [16] e a simulação de um sistema 3D é muito dispendiosa computacionalmente. A primeira realização experimental bidimensional da transição foi feita em 2007 por Spielman et al. [16], o que nos permite comparar nossos resultados.

A dissertação está organizada da forma como segue. Primeiramente, no capítulo 2, introduzimos o modelo de Bose-Hubbard, iniciando por uma revisão de aspectos gerais de sistemas periódicos e apresentando as hipóteses do modelo. Em seguida, no capítulo 3, discutimos algumas caracteríscas das fases SF e MI e utilizamos uma aproximação de campo médio para obter o diagrama de fases do sistema. No capítulo 4, apresentamos o algoritmo Worm, seus mecanismos de atualização, especificidades e sua aplicação ao modelo de Bose-Hubbard. No capítulo 5, mostramos nossos resultados numéricos obtidos com a simulação do algoritmo Worm. Comparamos o diagrama final obtido com esse algoritmo com o diagrama resultante da aproximação de campo médio e também comparamos nosso estudo com outros da literatura. Por fim, no capítulo 6, listamos nossos resultados, discutimos perspectivas e continuação. 


\section{Capítulo 2}

\section{O Modelo de Bose-Hubbard}

Este capítulo é dedicado ao estudo da dinâmica de um gás de bósons ultrafrios aprisionados em uma rede ótica. Após introduzir algumas características gerais do sistema, estudaremos o caso particular de uma partícula em um potencial periódico, onde conseguimos isolar os efeitos deste potencial. Estenderemos o estudo a um sistema de muitas partículas confinadas numa rede ótica periódica [17], adequando-o ao caso de interesse. Concluiremos que a dinâmica desses gases é bem descrita pelo modelo de Bose-Hubbard. Este modelo prevê uma transição de fase quântica onde o sistema passa de uma fase denominada superfluida (SF) a uma fase denominada isolante de Mott (MI) [8], que é o objeto de estudo deste trabalho.

\subsection{Gases bosônicos aprisionados em redes óticas}

A hamiltoniana que descreve um gás de $\mathrm{N}$ bósons confinados em um potencial externo é

$$
H_{0}=\sum_{i=1}^{N}\left[\frac{\mathbf{p}_{i}^{2}}{2 m}+V_{\text {ext }}\left(\mathbf{r}_{i}\right)\right]+\sum_{\substack{i, j \\ i \neq j}} V_{i n t}\left(\mathbf{r}_{i}, \mathbf{r}_{j}\right)
$$

em que $\mathbf{p}_{i}$ são os operadores momento de cada partícula, $V_{\text {ext }}$ descreve a ação de um potencial externo e $V_{i n t}$ é a interação entre as partículas do sistema. Note que aproximamos o último termo da hamiltoniana por um potencial de dois corpos, como argumentaremos, no sistema de interesse é razoável desprezar processos de colisão entre 3 ou mais partículas.

Por se tratar de um sistema de muitos corpos é conveniente utilizar o formalismo da segunda quantização, onde passamos a atuar no espaço de 
número de ocupação, o espaço de Fock (ver apêndice A para uma breve introdução no tema). Introduzindo os operadores de campo bosônicos, $\Psi$ e $\Psi^{\dagger}$, caracterizados pelas relações de comutação $\left[\Psi(\mathbf{r}), \Psi^{\dagger}\left(\mathbf{r}^{\prime}\right)\right]=\delta^{3}\left(\mathbf{r}-\mathbf{r}^{\prime}\right)$ e definindo a ação de operadores de um e dois corpos nesta representação (veja (A.10)), podemos reescrever a hamiltoniana (2.1), como

$$
H_{0}=\int d^{3} r d^{3} r^{\prime} \Psi^{\dagger}(\mathbf{r})\left(-\frac{\hbar^{2}}{2 m} \nabla^{2}+V_{\text {ext }}(\mathbf{r})+\Psi^{\dagger}\left(\mathbf{r}^{\prime}\right) V_{\text {int }}\left(\mathbf{r}, \mathbf{r}^{\prime}\right) \Psi\left(\mathbf{r}^{\prime}\right)\right) \Psi(\mathbf{r}) .
$$

No sistema que estudaremos, $V_{\text {ext }}$ representa uma rede ótica e a interação entre bósons nesta rede será substituída por uma interação efetiva definida a partir de considerações sobre gases ultrafrios diluídos. Portanto, antes de analisarmos essa hamiltoniana, faz-se necessário uma breve digressão.

\subsubsection{Interações}

Interações interatômicas dão origem a transições entre estados que, além de serem um mecanismo de perda de átomos armadilhados, complicam o tratamento do espalhamento já que devemos levar em conta mais graus de liberdade do sistema. Nas temperaturas de interesse, em que ocorre a condensação de Bose-Einstein $\left(T \sim 10^{-7} K\right)$, os átomos estão em seus estados fundamentais e portanto os únicos estados internos relevantes são os estados hiperfinos. A escala de energia da estrutura hiperfina para átomos alcalinos é da ordem de $10^{-4} K$ [18], o que significa que em uma escala de temperaturas abaixo desta, essas transições devido a interação podem ser desprezadas.

Em um gás diluído o alcance das forças interatômicas é muito menor que a distância média entre as partículas, i.e. $d \ll n^{-\frac{1}{3}}$, sendo $n$ a densidade do gás, e portanto colisões entre três ou mais corpos são eventos raros e podem ser desprezadas [18]. A natureza da interação entre dois átomos alcalinos (neutros), para separações atômicas pequenas, é repulsiva e para separações grandes, a interação atrativa de Van der Waals é dominante. Esta última é causada pela interação dipolo-dipolo elétrica entre dois átomos e tem a forma $-\alpha / r^{6}, \operatorname{com} r$ sendo a distância relativa entre os átomos. Assim, o potencial interatômico pode ser caracterizado por um potencial de curto alcance, com alcance $r_{0}$, e portanto podemos expandir a amplitude de espalhamento $f(\theta)$ em ondas parciais [19]. Esta depende apenas do ângulo de espalhamento $\theta$ e da magnitude do vetor de onda $k$ da onda espalhada.

No regime de energias muito baixas $\left(k r_{0} \ll 1\right)$ apenas ondas-s são relevantes no espalhamento e a amplitude de espalhamento se aproxima de uma 
constante, isto é,

$$
f_{k \rightarrow 0}(\theta)=-a,
$$

no qual o sinal negativo é adotado por convenção e a constante $a$ é denominada comprimento de espalhamento. Podemos calcular a seção de choque diferencial $d \sigma$, que é definida como a corrente da onda espalhada que passa através do ângulo sólido $d \Omega$ divida pelo fluxo da onda plana incidente, e obter

$$
\frac{d \sigma}{d \Omega}=\left|f_{k \rightarrow 0}(\theta)\right|^{2}=a^{2}
$$

Sendo assim, esperamos que apenas um parâmetro caracterize todos os efeitos das interações e o valor de $a$ corresponde, pela sua relação com a seção de choque, à escala de distâncias que caracteriza o alcance da interação. Ressaltamos que a interação é repulsiva para um $a>0$, do contrário, se $a<0$, a interação é atrativa [5]. Deste modo, podemos reescrever a condição de gás diluído como $n|a|^{3} \ll 1$.

Nestas condições podemos aproximar o potencial de interação real por um potencial efetivo caracterizado apenas pelo comprimento de espalhamento da onda-s,

$$
V_{\text {int }}\left(\mathbf{r}, \mathbf{r}^{\prime}\right)=g \delta^{3}\left(\mathbf{r}-\mathbf{r}^{\prime}\right)
$$

em que a constante g é denominada constante de acoplamento e se relaciona com $a$ através de $g=\frac{4 \pi \hbar^{2} a}{m}$, em que $m$ é a massa dos átomos. Portanto, o último termo do integrando em (2.2) é reescrito como

$$
V_{\text {int }}=\frac{4 \pi \hbar^{2} a}{m} \int d^{3} r \Psi^{\dagger}(\mathbf{r}) \Psi^{\dagger}(\mathbf{r}) \Psi(\mathbf{r}) \Psi(\mathbf{r}),
$$

e devemos dividir $V_{\text {int }}$ por um fator dois para descontar as interações repetidas.

\subsubsection{Redes óticas}

O padrão de interferência de lasers contrapropagantes gera um potencial periódico em que átomos neutros podem ser aprisionados. A periodicidade do potencial é determinada pelo comprimento de onda dos lasers. Por exemplo, se dois feixes têm o mesmo comprimento de onda $\lambda$, o período deste potêncial será $\lambda / 2$. Assim, podemos construir uma rede ótica com a sobreposição de ondas estacionárias, resultante da interferência de feixes contrapropagantes, perpendiculares entre si (figura 2.1). 
A interação resultante entre o campo elétrico do laser com o momento de dipolo induzido pela luz no átomo é responsável pelo confinamento dos átomos na rede [3]. Variando a frequência do laser, podemos atrair ou repelir os átomos das regiões de intensidade máxima do laser. Além disso, mudando a intensidade do laser, variamos a profundidade do potencial ótico confinante. Para criar um potencial de armadilhamento conservativo, utiliza-se frequências altas o suficientes para inibir eventos de espalhamento devido a absorção e emissão espontânea de fótons [20].

No caso mais simples, o potencial da rede ótica tem a forma aproximada

$$
V_{\text {ext }}=V_{0}\left[\operatorname{sen}^{2}\left(k x_{1}\right)+\operatorname{sen}^{2}\left(k x_{2}\right)+\operatorname{sen}^{2}\left(k x_{3}\right)\right],
$$

com vetor de onda $k=2 \pi / \lambda$, em que $\lambda$ é o comprimento de onda do laser, implicando em um período da rede igual a $\lambda / 2$ e $V_{0}$ é uma constante com unidades de energia. No contexto de redes óticas, a escala de energias é usualmente expressa em termos da enegia de recuo $E_{r}=\hbar^{2} k^{2} / 2 m$ [5].

Detalhes da teoria de aprisionamento de átomos neutros e outros detalhes experimentais da construção de redes óticas podem ser encontrados nas referências [20] e [5].
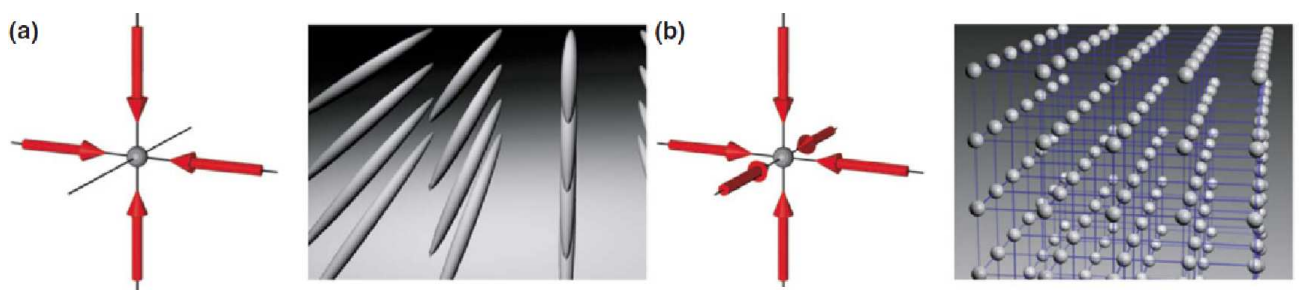

Figura 2.1: Redes óticas 2D (a) e 3D (b), formadas pela sobreposição de duas ou três ondas estacionárias perpendiculares entre si, respectivamente. (Figura extraída da referência [5].)

\subsection{Considerações a respeito de potenciais periódicos}

A presença de um potencial periódico impõe modificações à função de onda e à energia do espectro do sistema livre. A saber, a primeira passa a ter uma fase e a segunda a ser descrita por bandas, isto é, intervalos dentro dos quais as energias são aceitas, separadas por regiões nas quais as energias são proibidas [17]. 
A hamiltoniana de um átomo em um potencial periódico é

$$
H=-\frac{\hbar^{2}}{2 m} \nabla^{2}+U(\mathbf{r})
$$

em que $U(\mathbf{r})=U(\mathbf{r}+\mathbf{d})$, com $\mathbf{d}$ o período do potencial. É fácil verificar que esta hamiltoniana, por ter um potencial não constante, não possui invariância translacional contínua e portanto não há autoestados simultâneos com o operador momento. Porém, devido à periodicidade de seu potencial, ela possui uma invariância translacional discreta, o que significa que $H$ comuta com o operador $T_{\mathbf{d}}$ definido por

$$
T_{\mathbf{d}} f(\mathbf{r})=f(\mathbf{r}+\mathbf{d}) .
$$

De fato,

$$
\begin{gathered}
T_{\mathbf{d}} H \psi(\mathbf{r})=T_{\mathbf{d}} H T_{\mathbf{d}}^{-1} T_{\mathbf{d}} \psi(\mathbf{r})=H(\mathbf{r}+\mathbf{d}) \psi(\mathbf{r}+\mathbf{d})=H(\mathbf{r}) T_{\mathbf{d}} \psi(\mathbf{r}) \\
\therefore\left[H, T_{\mathbf{d}}\right]=0,
\end{gathered}
$$

em que usamos a periodicidade da hamiltoniana e que $T_{-\mathbf{d}}=T_{\mathbf{d}}^{-1}$. Com isso é possível estudar o espectro de $H$ através de uma análise do espectro de $T_{\mathbf{d}}$, já que $\left[H, T_{\mathbf{d}}\right]=0$ implica que há uma base de autoestados comum a esses operadores [21].

Para estudar o espectro de $T_{\mathbf{d}}$, note primeiramente que a aplicação seguida de $T_{\mathbf{d}}$ e $T_{\mathbf{d}^{\prime}}$ leva a um deslocamento $\mathbf{d}+\mathbf{d}^{\prime}$, que pode ser descrito pela ação de um único operador. De fato,

$$
T_{\mathbf{d}} T_{\mathbf{d}^{\prime}} \psi(\mathbf{r})=T_{\mathbf{d}^{\prime}} T_{\mathbf{d}} \psi(\mathbf{r})=\psi\left(\mathbf{r}+\mathbf{d}+\mathbf{d}^{\prime}\right)=T_{\mathbf{d}+\mathbf{d}^{\prime}} \psi(\mathbf{r})
$$

ou seja,

$$
T_{\mathbf{d}} T_{\mathbf{d}^{\prime}} \Psi(\mathbf{r})=c(\mathbf{d}) c\left(\mathbf{d}^{\prime}\right) \psi=T_{\mathbf{d}+\mathbf{d}^{\prime}} \psi=c\left(\mathbf{d}+\mathbf{d}^{\prime}\right) \psi .
$$

Assim, os autovalores de $T_{\mathbf{d}}$ devem obedecer à seguinte relação: $c(\mathbf{d}) c\left(\mathbf{d}^{\prime}\right)=$ $c\left(\mathbf{d}+\mathbf{d}^{\prime}\right)$. O que nos permite caracterizar a ação desse operador por exponenciais, $c(\mathbf{d})=e^{i \mathbf{q} \cdot \mathbf{d}}$, ou seja,

$$
T_{\mathbf{d}} \psi(\mathbf{r})=c(\mathbf{d}) \psi(\mathbf{r})=e^{i \mathbf{q} \cdot \mathbf{d}} \psi(\mathbf{r}) .
$$

O que acabamos de demonstrar é o chamado teorema de Bloch, que enuncia que sempre podemos escolher o autoestado $\psi$ de uma hamiltoniana periódica de modo a associar a cada $\psi$ um vetor $\mathbf{q}$ tal que $\psi(\mathbf{r}+\mathbf{d})=$ $e^{i \mathbf{q} \cdot \mathbf{d}} \psi(\mathbf{r})$. Chamamos os autoestados assim definidos de funções de Bloch. 
Uma forma alternativa desse teorema é afirmar que os autoestados $\psi_{n}$ de uma hamiltoniana com potencial periódico $U(\mathbf{r})=U(\mathbf{r}+\mathbf{d})$ podem ser escolhidos tais que

$$
\psi_{n \mathbf{q}}(\mathbf{r})=e^{i \mathbf{q} \cdot \mathbf{r}} u_{n \mathbf{q}}(\mathbf{r}),
$$

$\operatorname{com} u_{n \mathbf{q}}(\mathbf{r}+\mathbf{d})=u_{n \mathbf{q}}(\mathbf{r})$. Note ainda que

$$
\psi_{n \mathbf{q}}(\mathbf{r}+\mathbf{d})=e^{i \mathbf{q} \cdot(\mathbf{r}+\mathbf{d})} u_{n \mathbf{q}}(\mathbf{r}+\mathbf{d})=e^{i \mathbf{q} \cdot \mathbf{d}}\left[e^{i \mathbf{q} \cdot \mathbf{r}} u_{n \mathbf{q}}(\mathbf{r})\right],
$$

o que implica que $\psi_{n \mathbf{q}}(\mathbf{r}+\mathbf{d})=e^{i \mathbf{q} \cdot \mathbf{d}} \psi_{n \mathbf{q}}(\mathbf{r})$, de modo que reobtemos o enunciado anterior, provando a equivalência entre esses enunciados do teorema de Bloch. ${ }^{1}$

Concluímos então que a função de onda de uma partícula em um potencial periódico ganha uma fase igual a $e^{i \mathbf{q} \cdot \mathbf{r}}$ ao se deslocar de um sítio a outro de uma distância d. Para caracterizar melhor a função de onda dessa partícula, temos que nos restringir a um caso particular.

Se considerarmos baixas energias para a partícula presa no potencial ou o poço muito profundo, esta tenderá a estar localizada em um único sítio e uma solução estacionária de um único poço de potencial será uma boa descrição para ela. Por outro lado, se a energia desta partícula for alta ou os poços forem rasos, teremos partículas quase-livres e uma descrição de ondas planas é razoável. Como veremos, o sistema que iremos estudar está num regime de baixas energias e a função de onda da partícula tenderá a estar localizada no sítio. Embora, na transição de fase haverá a situação em que os poços serão rasos e a descrição de partículas isoladas não será tão apropriada. Para tanto precisamos buscar uma descrição que representa essas situações.

Uma aproximação que será adequada ao nosso caso é a conhecida como aproximação de tight-binding [17, 22]. Esta aproximação foi primeiramente utilizada no contexto do estado sólido. Foi desenvolvida para explicar as bandas de energias de metais de transição ou isolantes, nos quais o potencial dos íons pode ser aproximado por uma rede periódica, e lida com o caso em que a sobreposição entre orbitais atômicos vizinhos é tal que se precisa de correções a um modelo de átomos isolados.

Nesta aproximação consideramos que a função de onda nesse sistema

\footnotetext{
${ }^{1} \mathrm{~A}$ constante $\mathbf{q}$ introduzida é denominada quase-momento e é um número quântico característico de translações simétricas de potenciais periódicos. Recebe este nome pois pode ser visto como uma extensão natural do momento $\mathbf{p}$ em sistemas periódicos.
} 
deve ter a forma

$$
\psi_{\mathbf{q}}(\mathbf{r})=\sum_{\mathbf{d}} e^{i \mathbf{q} \cdot \mathbf{d}} \phi(\mathbf{r}-\mathbf{d})
$$

em que as funções $\phi(\mathbf{r}-\mathbf{d})$ são localizadas no sítio de posição $\mathbf{d}$ (múltiplo da periodicidade da rede). Note que esta função obedece o teorema de Bloch. Originalmente, $\phi(\mathbf{r}-\mathbf{d})$ é escolhida como uma combinação linear de orbitais atômicos de modo que a sobreposição entre funções de sítios vizinhos é pequena, levando à conclusão de que os orbitais atômicos a serem considerados em $\phi(\mathbf{r}-\mathbf{d})$ devem ser da mesma banda. A figura 2.2 ilustra esta função.

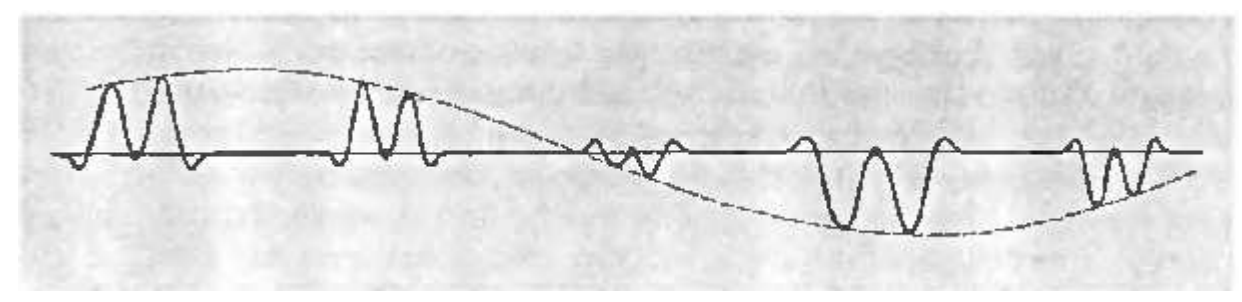

Figura 2.2: Função de onda da aproximação de tight-binding original. Os elétrons estão localizadas em íons de uma rede cristalina, cuja amplitude da sua função de onda é modelada pela fase definida pela função de Bloch. As funções localizadas $\phi(\mathbf{r}-\mathbf{d})$ são uma combinação linear de orbitais atômicos convenientes. (Figura extraída de [17].)

Uma função conveniente de ser trabalhada e que possui as propriedades de localização acima citadas é conhecida como função de Wannier (ver figura 2.3), e é definida como uma transformada de Fourier das funções de Bloch $\psi_{n \mathbf{q}}(\mathbf{r})$

$$
w_{n}(\mathbf{r}-\mathbf{d})=\frac{1}{\sqrt{N}} \sum_{\mathbf{q}} e^{-i \mathbf{q} \cdot \mathbf{d}} \psi_{n \mathbf{q}}(\mathbf{r})
$$

em que $N$ é o número de sítios da rede. Essas funções formam um conjunto 
completo ortonormal. De fato,

$$
\begin{aligned}
\int d^{3} r w_{n}^{*}(\mathbf{r}-\mathbf{d}) w_{n^{\prime}}\left(\mathbf{r}-\mathbf{d}^{\prime}\right) & =\frac{1}{N} \sum_{\mathbf{q} \mathbf{q}^{\prime}} e^{i \mathbf{q} \cdot \mathbf{d}} e^{-i \mathbf{q}^{\prime} \cdot \mathbf{d}^{\prime}} \int d^{3} r \psi_{n \mathbf{q}}^{*}(\mathbf{r}) \psi_{n^{\prime} \mathbf{q}^{\prime}}(\mathbf{r}) \\
& =\frac{1}{N} \sum_{\mathbf{q} \mathbf{q}^{\prime}} e^{i \mathbf{q} \cdot \mathbf{d}} e^{-i \mathbf{q}^{\prime} \cdot \mathbf{d}^{\prime}} \delta_{n n^{\prime}} \delta_{\mathbf{q} \mathbf{q}^{\prime}}^{3} \\
& =\frac{1}{N} \sum_{\mathbf{q}} e^{i \mathbf{q} \cdot\left(\mathbf{d}-\mathbf{d}^{\prime}\right)} \delta_{n n^{\prime}}=\delta_{n n^{\prime}} \delta_{\mathbf{d d}^{\prime}}^{3}
\end{aligned}
$$

Para provar essa relação usamos a ortonormalidade das funções de Bloch e, com condições de contorno adequadas, podemos provar que o somatório da última equação é igual ao delta de Kronecker $\delta_{\mathbf{d d}^{\prime}}^{3}$. Essas funções são uma ferramenta ideal para discutir fenômenos em que a localização espacial é importante [17].

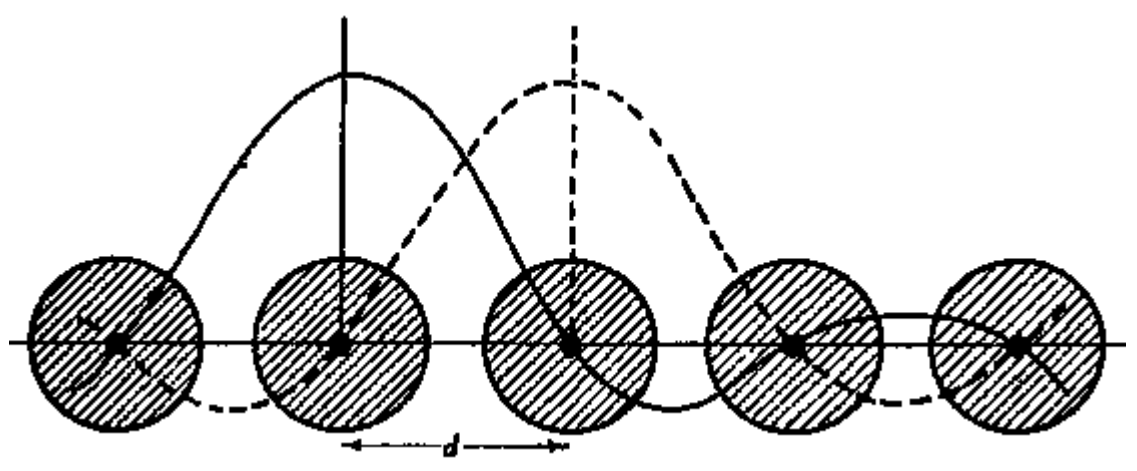

Figura 2.3: Funções de Wannier de sítios vizinhos. (Figura retirada de [22].)

\subsection{A hamiltoniana de Bose-Hubbard}

Estamos agora em condições de estudar o nosso problema, um gás ultrafrio de bósons armadilhados em um potencial periódico de uma rede ótica. Assim, voltamos à hamiltoniana do início deste capítulo (equações (2.2) e (2.6)), que reescrevemos aqui na forma

$$
H_{0}=\int d^{3} r \Psi^{\dagger}(\mathbf{r})\left(-\frac{\hbar^{2}}{2 m} \nabla^{2}+V_{e x t}(\mathbf{r})\right) \Psi(\mathbf{r})+\frac{g}{2} \int d^{3} r \Psi^{\dagger}(\mathbf{r}) \Psi^{\dagger}(\mathbf{r}) \Psi(\mathbf{r}) \Psi(\mathbf{r}) .
$$


Como as partículas estão confinadas em um potencial periódico e estamos em um regime de baixas temperaturas, uma descrição do tipo tight-binding é apropriada. As funções de Wannier neste contexto são uma representação adequada de átomos que tendem a estar localizados nos sítios da rede. Das propriedades dessas funções, podemos expandir os operadores de campo nesta base (veja (A.3)),

$$
\begin{aligned}
\Psi(\mathbf{r}) & =\sum_{n, i} w_{n}\left(\mathbf{r}-\mathbf{d}_{i}\right) b_{n, i} \\
\Psi^{\dagger}(\mathbf{r}) & =\sum_{n, i} w_{n}^{*}\left(\mathbf{r}-\mathbf{d}_{i}\right) b_{n, i}^{\dagger}
\end{aligned}
$$

sendo $b_{n, i}$ e $b_{n, i}^{\dagger}$, respectivamente, os operadores de aniquilação e criação de uma partícula da banda $n$ no sítio $i$ (veja as equações (A.4) e (A.6) para definição).

Outra aproximação conveniente e que é consistente com a aproximação de tight-binding, é supor que as energias envolvidas na dinâmica do sistema são pequenas comparadas com a energia de excitação da segunda banda [8]. Sendo assim, consideraremos apenas a banda de energia mais baixa, isto é, $w_{0}$ e $b_{0, i}$ (passaremos a omitir os índices de banda).

Assim, substituindo a expansão (2.20) na hamiltoniana (2.19), obtemos

$$
H_{0}=-\sum_{i j} J_{i j} b_{i}^{\dagger} b_{j}+\frac{1}{2} \sum_{i j k l} U_{i j k l} b_{i}^{\dagger} b_{j}^{\dagger} b_{k} b_{l},
$$

em que os elementos de matriz $J_{i j}$ e $U_{i j k l}$ são definidos como

$$
\begin{gathered}
J_{i j}=-\int d^{3} r w^{*}\left(\mathbf{r}-\mathbf{d}_{\mathbf{i}}\right)\left[-\frac{\hbar^{2}}{2 m} \nabla^{2}+V_{e x t}(\mathbf{r})\right] w\left(\mathbf{r}-\mathbf{d}_{\mathbf{j}}\right), \\
U_{i j k l}=g \int d^{3} r w^{*}\left(\mathbf{r}-\mathbf{d}_{\mathbf{i}}\right) w^{*}\left(\mathbf{r}-\mathbf{d}_{\mathbf{j}}\right) w\left(\mathbf{r}-\mathbf{d}_{\mathbf{k}}\right) w\left(\mathbf{r}-\mathbf{d}_{\mathbf{l}}\right) .
\end{gathered}
$$

Identificamos o termo $J_{i j}$ como o ganho em energia cinética devido ao tunelamento de uma partícula do sítio $i$ para o $j$, no qual vale salientar a dependência do potencial externo (2.7), cuja amplitude $V_{0}$ pode ser variada mudando a intensidade do laser. Já $U_{i j k l}$ representa a interação entre as partículas dos sítios $i, j, k$ e $l$.

Consideraremos que a interação interatômica é repulsiva e local, no sentido em que $U=U_{i j k l} \neq 0$ apenas para $i=j=k=l$. Supomos ainda que a possibilidade de tunelamento das partículas ocorre apenas entre sítios vizinhos, assim $J=J_{i j} \neq 0$ apenas para primeiros vizinhos. Veja que essas simplificações são consequências das aproximações feitas. De fato, contanto que 
a altura da barreira seja suficientemente alta, a sobreposição entre funções de Wannier de sítios vizinhos será pequena e essas considerações serão bastante razoáveis. Assim, obtemos a hamiltoniana de Bose-Hubbard,

$$
H_{0}=-J \sum_{\langle i, j\rangle} b_{i}^{\dagger} b_{j}+\frac{U}{2} \sum_{i} b_{i}^{\dagger} b_{i}^{\dagger} b_{i} b_{i},
$$

em que $\langle i, j\rangle$ representa a soma feita apenas nos primeiros vizinhos e, como dito acima, $J$ é o elemento da matriz de tunelamento entre sítios vizinhos e $U$ corresponde à intensidade da repulsão entre dois átomos em um mesmo sítio.

Variando a intensidade dos lasers que formam a rede (isto é, variando a profundidade $V_{0}$ dos poços) podemos variar a razão entre $U$ e $J$, pois com o aumento da profundidade as funções atômicas se tornam mais localizadas, fazendo com que a interação intra-sítio $U$ aumente e, ao mesmo tempo, o elemento de matriz de tunelamento $J$ diminua [8]. Variando essa razão podemos induzir no sistema uma transição de fase, passando de um regime deslocalizado, denominado fase superfluida (SF), para um regime localizado, a fase isolante de Mott (MI). O objetivo deste trabalho é caracterizar essa transição de fase construíndo um diagrama de fases (DF).

Na tabela 2.1 vemos que à medida que a profundidade do poço de potencial $V_{0}$ aumenta, os valores do elemento de matriz de tunelamento para primeiros vizinhos $J$ diminuem, assim como a largura da primeira banda $W$. Também vemos que a função de Wannier se aproxima de uma gaussiana, o estado fundamental $\phi$ da rede ótica $1 \mathrm{D}$, isto é, se torna mais isolada. Ratificando assim, as aproximações e considerações feitas até então. Veja que mesmo em profundidades de poços rasos a sobreposição da função de Wannier é próxima de 1 e os valores do elemento de matriz de tunelamento para segundos vizinhos $J(2 d)$ são desprezíveis.

Trabalhar no ensemble grande canônico será mais conveniente porque neste o número de partículas não é fixo. Além disso, um diagrama de fases para o sistema é obtido neste formalismo. Passamos para este ensemble ao minimizar $\left\langle H-\mu \sum_{i} \hat{n}_{i}\right\rangle$ [4] de modo que obtemos a hamiltoniana que será usada ao longo deste trabalho:

$$
H=-J \sum_{\langle i, j\rangle} b_{i}^{\dagger} b_{j}+\frac{U}{2} \sum_{i} \hat{n}_{i}\left(\hat{n}_{i}-1\right)-\mu \sum_{i} \hat{n}_{i} .
$$

O potencial químico $\mu$ age de maneira a fixar o número médio de partículas do sistema. Note que utilizamos as relações de comutação (A.4) para simplificar o segundo termo da hamiltoniana acima colocando-a em função do 


\begin{tabular}{ccccc}
\hline \hline$V_{0} / E_{r}$ & $4 J / E_{r}$ & $W / E_{r}$ & $J(2 d) / J$ & $|\langle w \mid \phi\rangle|^{2}$ \\
\hline 3 & 0.444109 & 0.451894 & 0.101075 & 0.9719 \\
5 & 0.263069 & 0.264211 & 0.051641 & 0.9836 \\
10 & 0.076730 & 0.076747 & 0.011846 & 0.9938 \\
15 & 0.026075 & 0.026076 & 0.003459 & 0.9964 \\
20 & 0.009965 & 0.009965 & 0.001184 & 0.9975 \\
\hline \hline
\end{tabular}

Tabela 2.1: Valores do elemento de matriz de tunelamento para primeiros vizinhos $J$ e segundos vizinhos $J(2 d)$; largura da banda mais baixa, $W$; e a projeção da função de Wannier, $w$, no estado fundamental gaussiano local, $\phi$, para um potencial puramente senoidal 1D; em diferentes profundidades do poço de potencial $V_{0}$ em unidades da energia de recuo, $E_{r}$. (Tabela extraída de [5].)

operador de número $\hat{n}_{i}=b_{i}^{\dagger} b_{i}$, cujo espectro no espaço de Fock está associado ao número de partículas no sítio $i$ (ver (A.9)). 


\section{Capítulo 3}

\section{Um estudo preliminar do modelo}

No capítulo anterior, construímos a hamiltoniana de Bose-Hubbard, que será utilizada para descrever nosso sistema físico. Aqui faremos um estudo teórico daquela hamiltoniana utilizando uma aproximação de campo médio (CM). Descreveremos a transição de fase prevista por esse modelo qualitativamente e apresentaremos algumas de suas características. Também obteremos um diagrama das fases do sistema diagonalizando numericamente a hamiltoniana resultante da aproximação feita, obtendo uma estimativa da fronteira da transição que está qualitativamente correta. Conseguimos estimar o valor do ponto crítico da transição que pode ser verificado numericamente nas referências $[12,13]$ e analiticamente em [24].

\subsection{A transição de Mott}

Uma transição de fase muda as propriedades de um sistema de maneira abrupta. Se o sistema se encontra à temperatura zero, todas as flutuações térmicas estão congeladas e portanto não pode acontecer nenhuma transição de fase em um sistema clássico. Porém, em um sistema quântico existem flutuações presentes mesmo no zero absoluto devido ao princípio de incerteza de Heisenberg. Essas flutuações quânticas microscópicas podem ser fortes o suficiente para induzir uma transição de fase quântica macroscópica no estado fundamental [7].

Um exemplo de transição puramente quântica ocorre em um sistema de partículas bosônicas aprisionadas em uma rede periódica descrito pela 
hamiltoniana (2.25), que reescrevemos abaixo

$$
H=-J \sum_{\langle i, j\rangle} b_{i}^{\dagger} b_{j}+\frac{U}{2} \sum_{i} \hat{n}_{i}\left(\hat{n}_{i}-1\right)-\mu \sum_{i} \hat{n}_{i},
$$

esta transição é conhecida como transição de Mott. A temperatura zero, a competição entre os termos $U$ e $J$ da hamiltoniana que quantificam, respectivamente, a interação entre partículas e o tunelamento de partículas entre sítios da rede, levam o sistema a uma transição de fase. No caso extremo em que $J \gg U$, as partículas tunelam facilmente de um sítio a outro, portanto o sistema está em um regime deslocalizado e se encontra na fase denominada superfluida (SF). Já no limite oposto, em que $J \ll U$, o preço energético por mover uma partícula para outro sítio é alto, suprimindo a flutuação do número de partículas por sítio e o sistema é dito estar na fase isolante de Mott (MI).

Considerando o caso particular em que $J=0$, a energia da hamiltoniana (3.1) pode ser escrita em termos da energia por sítio $\varepsilon\left(n_{i}\right)=n_{i}\left(n_{i}-1\right) U / 2-$ $\mu n_{i}$, sendo $n_{i}$ o número de ocupação do sítio $i$. Assim, a energia do estado fundamental do sistema pode ser encontrada minimizando $\varepsilon\left(n_{i}\right)$.

Quando o número de ocupação de um sítio do sistema é aumentado de $\delta$, a energia deste muda para

$$
\varepsilon\left(n_{i}+\delta\right)=\varepsilon\left(n_{i}\right)+\varepsilon(\delta)+U n_{i} \delta
$$

portanto o aumento na energia deste sítio é de $\varepsilon(\delta)+U n_{i} \delta$, sendo que $\varepsilon(\delta)$ é o resultado da interação entre as partículas colocadas em $i$ e $n_{i} U \delta$ é a interação destas com as que já estavam no sítio. Ou seja, há uma penalidade energética por uma ocupação maior que 1 de um sítio.

Sendo assim, considerando uma rede com $N$ sítios, ao adicionarmos duas partículas nesta rede, o estado de menor energia será qualquer configuração em que estas estão em sítios diferentes. Adicionando sucessivamente uma partícula por vez nesse sistema, para mantê-lo no estado de mínima energia, devemos ir preenchendo um sítio de cada vez. Ao chegar a $N$ partículas na rede, o estado fundamental do sistema será uma rede em que cada sítio tem um fator de preenchimento um, ou seja, há uma partícula por sítio. Uma figura ilustrativa desta situação é a 3.1(b).

O autoestado para o sistema neste caso é igual a um produto de estados de Fock locais para cada sítio da rede e, como discutido, no caso em que temos $N$ sítios e com fator de preenchimento $n$ o estado fundamental do 
sistema, a menos de uma constante de normalização, será [7]

$$
\left|\Psi_{M I}\right\rangle^{J=0} \propto \prod_{i=1}^{N}\left(b_{i}^{\dagger}\right)^{n}|0\rangle .
$$

A existência de um gap de energia no espectro da fase Mott tem uma implicação fundamental nas propriedades dessa fase. Para colocar uma partícula em um sítio o ganho de energia é $U n_{i}-\mu$ e, para se retirar, é $-\left[U\left(n_{i}-1\right)-\mu\right]$. Assim, ao variar o potencial químico entre os valores $U\left(n_{i}-1\right)$ e $U n_{i}$, a densidade por sítio não muda, ou seja, $\partial n_{i} / \partial \mu=0$. Chamamos esta propriedade de incompressibilidade. Esta é na verdade a propriedade que define a fase MI e não a existência de estados de Fock locais já que esses existem apenas em $J=0$ [5]. Note que se $\mu=U n_{i}$, a energia do sistema é degenerada para estado com uma densidade entre $n_{i}+1$ e $n_{i}$ e neste caso o fluido é compressível [23]. O gap de energia para uma situação indermediária (em que $J \neq 0$ ) diminui à medida que o termo de tunelamento aumenta até desaparecer na fase SF.

Se considerarmos agora $U=0$, temos que as partículas tunelam entre os sítios sem penalidade energética. A hamiltoniana do sistema neste limite pode ser diagonalizada no espaço de momentos $k$ e portanto, podemos escrever o autoestado desta como $\prod_{i=1}^{N} b_{k_{i}}^{\dagger}|0\rangle$. Já que não há interação, esperamos que todos os $M$ átomos desta rede estejam no estado de menor energia $(k=0)$, sendo assim o estado fundamental do sistema será [7]

$$
\left|\Psi_{S F}\right\rangle^{U=0} \propto\left(\sum_{i=1}^{N} b_{i}^{\dagger}\right)^{M}|0\rangle .
$$

Novamente, este estado não está normalizado.

Podemos ter uma visualização de como os átomos se distribuem na rede analisando este estado fundamental. De fato, fatorando o termo $\left(\sum_{i=1}^{N} b_{i}^{\dagger}\right)^{M}$, visualizamos que em cada termo um átomo terá uma probabilidade independente dos outros átomos da rede de estar em um sítio. No limite em que $M$ e $N$ são grandes, o número de átomos em cada sítio da rede é uma distribuição de Poisson. Uma figura ilustrativa desta situação é a 3.1(a). Note que a fase superfluida não possui um gap de energia no espectro de excitação e portanto a fase é compressível.

Voltando a considerar a situação de uma rede com $N$ sítios com fator de preenchimento um, ao adicionar uma partícula a esse sistema esta irá receber uma penalidade energética pequena por se mover, já que sua energia 
de interação será a mesma em qualquer sítio da rede. Por essa razão dizemos que um gás com um número não-inteiro de bósons em cada sítio estará em uma fase superfluida à temperatura zero [24].

Se desligarmos a rede ótica do sistema e deixarmos o gás expandir livremente, as figuras resultantes do padrão de interferência dependerão de cada fase. Isto pode ser visto na figura 3.1, onde à direita da representação de cada uma das fases há sua respectiva imagem de interferência. Na fase SF temos picos de interferência bem definidos, enquanto que na fase isolante não há nenhum padrão de interferência. Os picos são devido a periodicidade da rede e exigem uma fase macroscópica constante ao longo dos sítios da rede. O que demonstra que na fase superfluida há uma coerência através da rede que desaparece na fase MI. Desconsiderando o efeito das interações durante a expansão, a distribuição de momentos representa a transformada de Fourier da função de onda macroscópica original na rede e, portanto, o arranjo dos picos de momento corresponde a rede recíproca $[7,20]$.

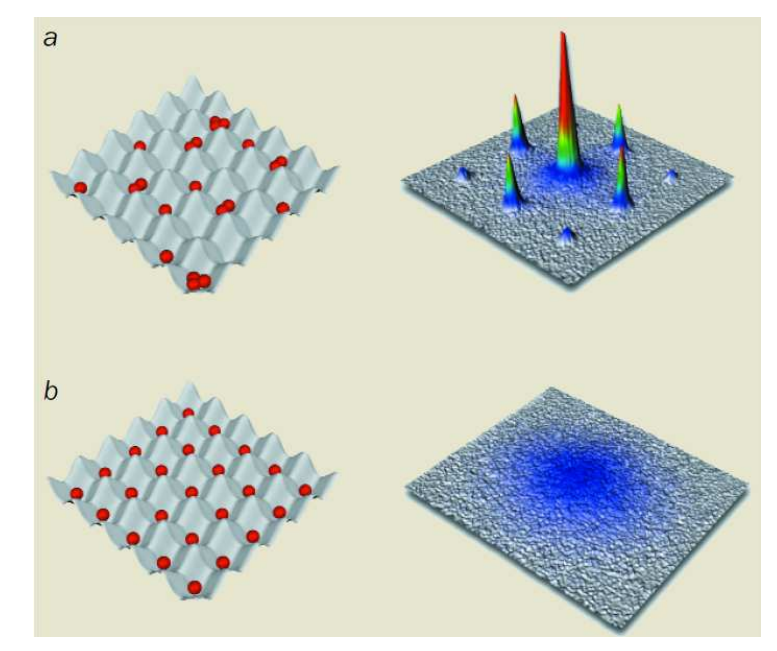

Figura 3.1: Um desenho esquemático das fases SF (a) e MI (b). Na fase SF o termo de tunelamento é dominante favorecendo um estado deslocalizado. Já na fase MI, o termo de interação é dominante desfavorecendo a movimentação de partículas e, portanto, temos um estado localizado. À direita, as imagens de interferência das respectivas fases. (Figura retirada da referência [3].)

Estudaremos na seção seguinte esta transição fazendo uso de uma aproximação de campo médio, construindo o diagrama de fases (DF) do sis- 
tema. Um diagrama de fases mostra as condições nas quais fases distintas podem ocorrer num sistema. No caso, dois parâmetros são fundamentais para determinar as possíveis fases em que o gás pode estar: $J$ e $U$. Como dissemos anteriormente, é mais interessante termos um diagrama de fases caracterizado também pelo potencial químico já que assim a condição de que o número de átomos é fixo é removida, obtendo uma informação adicional. Assim, a fase do sistema será determinada pelos valores de $\mu, J$ e $U$. Usamos apenas o fator de preenchimento para diferenciar as fases na construção de um DF, que é inteiro na fase Mott e não-inteiro na fase SF. Porém, há outros observáveis que podem ser usados para diferenciar as fases do sistema como por exemplo a compressibilidade.

\subsection{Uma aproximação de campo médio}

Fisher et al. [9] desenvolveram uma teoria de campo médio que leva a um diagrama de fases que está qualitativamente correto, delimitando a fronteira de transição entre a fase superfluida e a fase isolante de Mott. O estudo com essa teoria nos trará um melhor entendimento do sistema, e o diagrama de fases resultante nos servirá de guia para verificar os resultados numéricos que serão obtidos com o algoritmo de Monte Carlo Quântico no capítulo 5.

Usualmente uma aproximação de campo médio consiste em aproximar um termo de dois corpos, como as interações atuantes em um sistema de muitos corpos, por uma média ou interação efetiva. Uma teoria padrão de campo médio é a de Bogoliubov [24], na qual substituímos o operador de criação e aniquilação pela sua média, denotada por $\sqrt{N_{0}}$, mais uma flutuação $b_{0}^{\dagger} \rightarrow \sqrt{N_{0}}+b_{0}^{\dagger}$ e $b_{0} \rightarrow \sqrt{N_{0}}+b_{0}$, e minimizamos a energia do gás com respeito ao número de átomos no condensado. Nesta expressão $N_{0}$ é o número de partículas no condensado e consideramos $N_{0} \gg 1$. Porém, essa descrição não prevê a transição de Mott em duas e três dimensões. Isto acontece porque tratamos aproximadamente as interações e, como visto na seção anterior, a interação é importante para ocorrer a transição SF-MI. A teoria que iremos desenvolver ao longo dessa seção trata exatamente a interação e aproxima a energia cinética dos átomos na rede, i.e., aproxima o termo de um corpo.

Para chegar em uma aproximação de campo médio que descreve a transição de Mott, iremos considerar a média das flutuações quânticas (tunelamento) sentidas pelo sistema. Como consequência, o termo cinético irá se desacoplar. Essencialmente, o que fazemos é uma aproximação de campo 
médio local [12], na qual

$$
\left(b_{i}^{\dagger}-\left\langle b_{i}^{\dagger}\right\rangle\right)\left(b_{j}-\left\langle b_{j}\right\rangle\right) \approx 0
$$

e portanto

$$
\begin{aligned}
b_{i}^{\dagger} b_{j} & =\left\langle b_{i}^{\dagger}\right\rangle b_{j}+\left\langle b_{j}\right\rangle b_{i}^{\dagger}-\left\langle b_{i}^{\dagger}\right\rangle\left\langle b_{j}\right\rangle \\
& =\phi\left(b_{i}^{\dagger}+b_{j}\right)-\phi^{2}
\end{aligned}
$$

em que introduzimos $\phi=\left\langle b_{i}^{\dagger}\right\rangle=\left\langle b_{i}\right\rangle$. É possível mostrar que $\phi$ constitui um parâmetro de ordem para a transição, ou seja, é igual a zero na fase isolante e tem um valor diferente de zero para o estado superfluido [13].

Considerando a hamiltoniana de Bose-Hubbard (3.1), e substituindo a aproximação (3.6) obtemos

$$
\begin{aligned}
H^{C M} & =-J \sum_{\langle i, j\rangle}\left[\phi\left(b_{i}^{\dagger}+b_{j}\right)-\phi^{2}\right]+\frac{U}{2} \sum_{i} \hat{n}_{i}\left(\hat{n}_{i}-1\right)-\mu \sum_{i} \hat{n}_{i} \\
& =-z J \phi \sum_{i}\left(b_{i}^{\dagger}+b_{i}\right)+z N J \phi^{2}+\frac{U}{2} \sum_{i} \hat{n}_{i}\left(\hat{n}_{i}-1\right)-\mu \sum_{i} \hat{n}_{i},
\end{aligned}
$$

sendo $N$ o número de sítios e $z=2 d$, definido como o número de primeiros vizinhos da rede, com $d$ a dimensão do sistema. Portanto, podemos usar apenas a hamiltoniana de campo médio de um sítio:

$$
H_{i}^{C M}=-z J \phi\left(b_{i}^{\dagger}+b_{i}\right)+z J \phi^{2}+\frac{U}{2} \hat{n}_{i}\left(\hat{n}_{i}-1\right)-\mu \hat{n}_{i},
$$

em que $\hat{n}_{i}$ é o operador de número. Veja que com essa aproximação passamos a tratar todos os sítios independentemente.

\subsection{Diagrama de fases I}

O diagrama de fases de um gás de bósons ultrafrio numa rede ótica descrito utilizando a aproximação de campo médio discutida anteriormente foi obtido numericamente de maneira autoconsistente. A partir do parâmetro de ordem $\phi$ conseguimos determinar a hamiltoniana de campo médio $H^{C M}$ que descreve o gás. Por sua vez, $H^{C M}$ nos permite obter o estado fundamental do sistema. Por fim, o conhecimento do estado fundamental nos permite reobter o parâmetro de ordem $\phi$. Surge aí um critério de autoconsistência para a determinação do estado fundamental do sistema: o parâmetro de ordem obtido a partir do estado fundamental deve ser igual ao que determina este estado. 
O procedimento para determinar o estado fundamental a partir de um dado $\phi$ consiste em resolver uma equação de autovalores para a hamiltoniana de um corpo (3.8), para isto iremos usar a representação matricial. Como o problema se reduziu ao tratamento de um sítio independente, o índice $i$ será omitido. Utilizando a base de número de ocupação $|n\rangle$, podemos representar os operadores $b$ e $b^{\dagger}$ explicitamente [25]

$$
b=\left[\begin{array}{ccccc}
0 & 1 & 0 & 0 & \cdots \\
0 & 0 & \sqrt{2} & 0 & \cdots \\
0 & 0 & 0 & \sqrt{3} & \cdots \\
0 & 0 & 0 & 0 & \\
\vdots & \vdots & \vdots & & \ddots
\end{array}\right] \quad b^{\dagger}=\left[\begin{array}{ccccc}
0 & 0 & 0 & 0 & \cdots \\
1 & 0 & 0 & 0 & \cdots \\
0 & \sqrt{2} & 0 & 0 & \cdots \\
0 & 0 & \sqrt{3} & 0 & \\
\vdots & \vdots & \vdots & & \ddots
\end{array}\right]
$$

Portanto, o operador de número será dado por:

$$
\hat{n}=b^{\dagger} b=\left[\begin{array}{ccccc}
0 & 0 & 0 & 0 & \cdots \\
0 & 1 & 0 & 0 & \cdots \\
0 & 0 & 2 & 0 & \cdots \\
0 & 0 & 0 & 3 & \\
\vdots & \vdots & \vdots & & \ddots
\end{array}\right]
$$

(Note que, para construir essas matrizes, utilizamos as relações (A.6).)

Para o estudo da transição de fase, escalonaremos a hamiltoniana como $H=U \bar{H}$ e estudaremos as transições de $\bar{H}$ que, na forma matricial é dada explicitamente por

$$
\overline{\mathbb{H}}^{C M}=-z \frac{J}{U} \phi\left(b^{\dagger}+b\right)+z \frac{J}{U} \phi^{2} \mathbb{1}+\frac{1}{2} \hat{n}(\hat{n}-1)-\frac{\mu}{U} \hat{n} .
$$

Começamos o procedimento chutando um valor inicial para o parâmetro de ordem $\phi$, e ficamos com apenas dois parâmetros, $\bar{J}=\frac{J}{U}$ e $\bar{\mu}=\frac{\mu}{U}$ a serem definidos. Para obter o estado fundamental dessa hamiltoniana, a diagonalizamos numa base truncada $|N\rangle$, com $N=0, \ldots, N_{\max }$, o que nos permitirá encontrar seus autovalores. Então, o estado fundamental de $\mathbb{H}^{C M}$ será

$$
|G\rangle=\sum_{N=0}^{N_{\max }} \alpha_{N}|N\rangle,
$$

em que os coeficientes $\alpha_{N}$ correspondem ao mais baixo autovalor da matriz (3.11) na base truncada e normalizam $|G\rangle$. 
Assim, podemos determinar o parâmetro de ordem correspondente ao estado fundamental encontrado, que pode ser calculado como

$$
\phi^{\prime}=\left\langle G\left|b^{\dagger}\right| G\right\rangle .
$$

O procedimento é repetido até que o critério de autoconsistência, $\phi^{\prime}=\phi$, seja cumprido. Quando isso ocorrer, poderemos calcular a ocupação média por sítio como

$$
\rho=\langle n\rangle=\sum_{N=1}^{N_{\max }}\left|\alpha_{N}\right|^{2} N .
$$

Podemos resumir este algoritmo em um diagrama de fluxo:

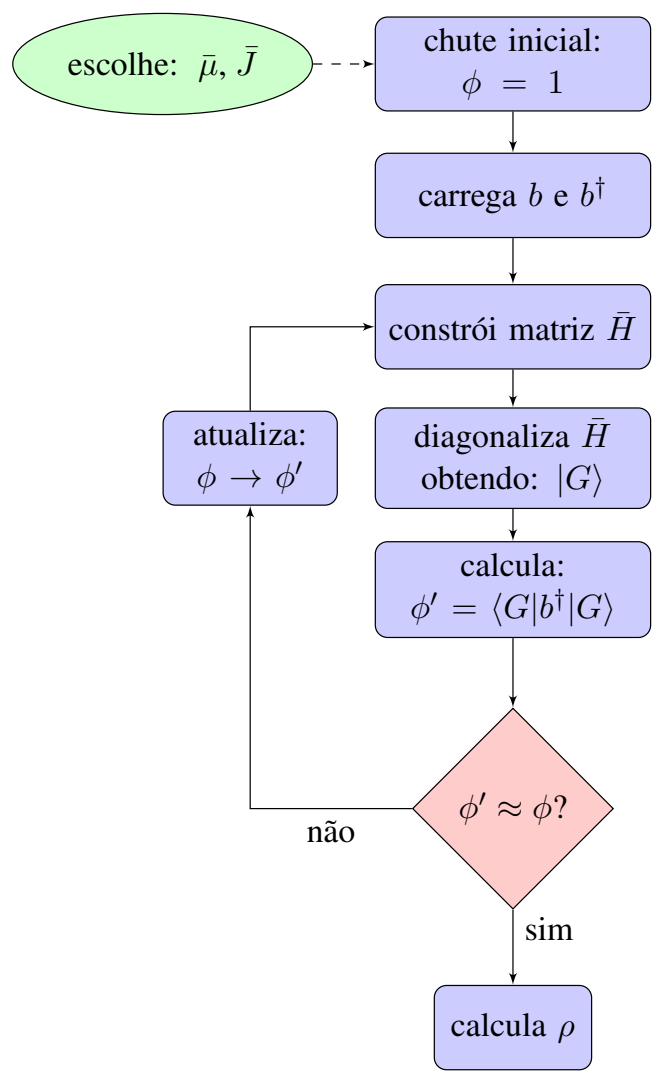

Figura 3.2: Fluxograma do algoritmo que estima a densidade por sítio $\rho$ na aproximação de campo médio. 
Como haviamos dito $\phi$ é um parâmetro de ordem da transição de Mott, agora podemos comprová-lo na figura 3.3 gerada com o algoritmo previamente descrito.

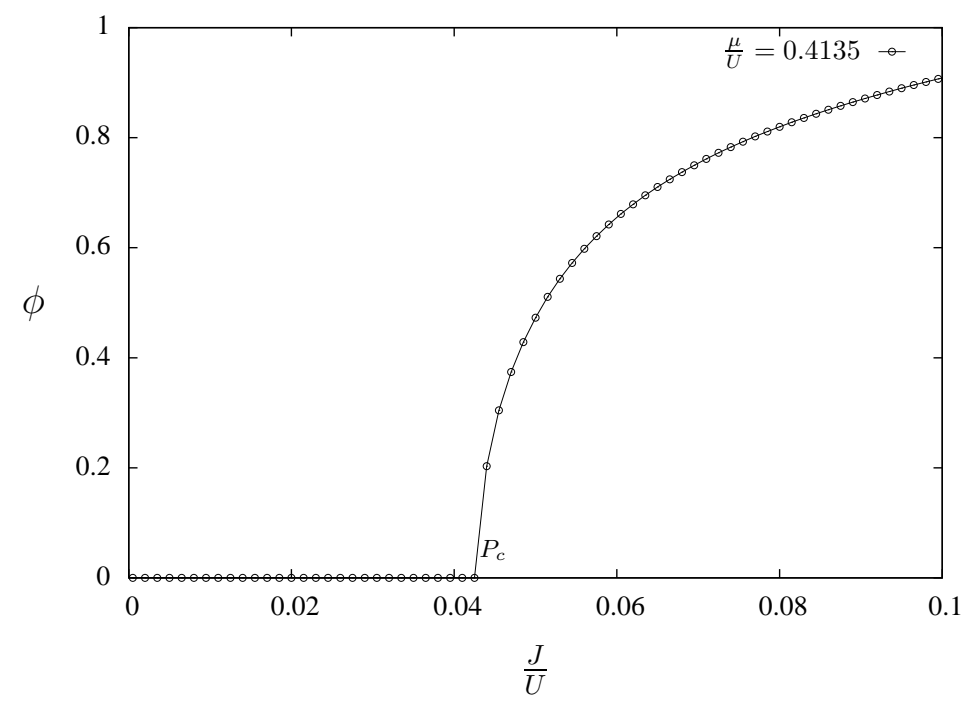

Figura 3.3: Parâmetro de ordem da transição de Mott. O ponto $P_{c}$ indicado no gráfico é igual a 0.0430 .

Usualmente o diagrama de fases desta transição é representado pelas relações entre $\mu / U$ e $J / U$ mas, alguns autores usam o inverso da última relação, isto é $U / J$. Porém, ao desenhar o diagrama da última maneira as regiões em que há a fase Mott não ficam completamente delimitadas. Já que teoricamente não precisamos por restrições no valor da interação e nesta representação a fase Mott vai existir a partir de um certo valor de $U / J$ e persistirá até o infinito. Acreditamos que o entendimento e a visualização do diagrama ficam facilitados utilizando a primeira descrição e por isso ao longo de todo o trabalho usaremos $J / U$ para caracterizar o sistema. Note que este diagrama é geral, no sentido que todos sistemas descritos pelo modelo de $\mathrm{BH}$ possuirão este mesmo DF, já que ele depende apenas de valores relativos de $U, J$ e $\mu$.

O diagrama de fases é desenhado a partir do conhecimento da densidade por sítio (3.14) do estado fundamental da hamiltoniana $H^{C M}$ à medida que mudamos as variáveis $J / U$ e $\mu / U$. Contabilizamos os pontos do plano $(J / U, \mu / U)$ em que a densidade passa de um valor inteiro a um não-inteiro. Então a fronteira de transição entre as fases SF-MI será determinada por 
esses pontos. Uma descrição mais detalhada dos critérios utilizados na construção dos diagramas de fases será feita no capítulo 5 .

A figura 3.4 é o resultado deste procedimento, onde consideramos a rede quadrada e bidimensional (ou seja, $z=4$ ). Vemos que a região em que ocorre a fase Mott no diagrama é fechada em "platôs" com densidade constante e inteira. Cada platô com densidade por sítio $\rho$ constante é conhecido como lobo de Mott. Nessa figura, temos os três primeiros lobos de Mott com fator de preenchimento $\rho=1, \rho=2$ e $\rho=3$.

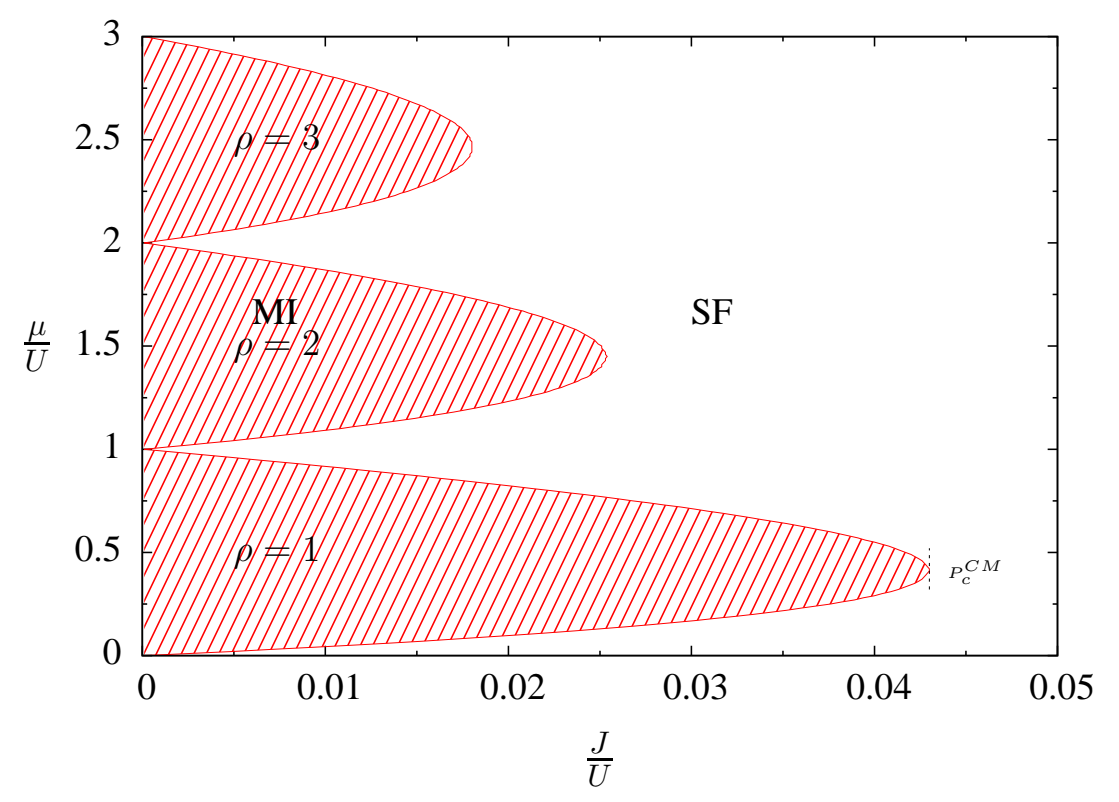

Figura 3.4: Diagrama de fases desenhado a partir de uma aproximação de campo médio com $z=4$. Este diagrama apresenta os três primeiros lobos de Mott (fundo hachurado), isto é regiões na fase Mott bem delimitadas e com um mesmo fator de preenchimento $\rho$ inteiro, como indicado em cada lobo. A fase superfluida é caracterizada por um $\rho$ não-inteiro. $\mathrm{O}$ valor do ponto crítico para o primeiro lobo de Mott é $P_{c}^{C M}=(0.0430 \pm 0.0001,0.4135 \pm$ $0.0003)$.

Os pontos mais extremos dos lobos de Mott são pontos especiais desta transição de fase e são denominados de pontos críticos e a região ao seu redor de região crítica da transição. Por hora estes pontos serão apenas uma referência a ser comparada com os valores encontrados na literatura, e no capítulo 5 discutiremos a importância desses pontos. Entretanto, nos res- 
tringiremos em estimar apenas o ponto crítico para o primeiro lobo de Mott e sempre que nos referirmos ao ponto crítico da transição ao longo do texto, estaremos falando do primeiro lobo, fora menção explicita do contrário.

O valor do ponto crítico da transição de fase obtido a partir do nosso gráfico é $P_{c}^{C M}=(0.0430 \pm 0.0001,0.4135 \pm 0.003)$, onde o erro é atribuido apenas ao tamanho do passo de $J / U$ e $\mu / U$ utilizado na varredura do diagrama. Este valor é o mesmo que o encontrado em [13] (onde $(J / U)_{c}=$ 0.043 ) e corresponde ao valor $(U / z J)_{c} \approx 5.83$ (ou seja, $(J / U)_{c}=0.0429$ ) estimado em [12], com o mesmo método utilizado aqui, e em [24], utilizando uma teoria de perturbação. 


\section{Capítulo 4}

\section{Monte Carlo Quântico}

Introduziremos o algoritmo de Monte Carlo Quântico conhecido como algoritmo Worm aplicado ao modelo de Bose-Hubbard. Primeiramente deduziremos a função de partição de um sistema de muitos corpos em termos de integrais de caminho que são a base para a construção do algoritmo [15]. Os observáveis do sistema podem ser calculados a partir da função de partição. Em seguida, apresentaremos o algoritmo Worm que foi utilizado para obter um diagrama de fases para o modelo estudado e cujos resultados serão apresentados no capítulo 5. Por fim, discutiremos algumas características desse algoritmo ${ }^{12}$.

\subsection{O método de Monte Carlo clássico}

O método de Monte Carlo (MC) é uma ferramenta numérica bastante poderosa principalmente quando aplicada a sistemas grandes ou com muitos graus de liberdade. Com ela, problemas determinísticos são tratados achando um análogo probabilístico que, definidos os pesos estatísticos das configurações ou propriedades relevantes do sistema, após um certo tempo de simulação, chega perto da resposta exata do problema original.

De maneira geral, podemos definir uma estratégia de resolução usual em simulações de MC. Primeiramente define-se o domínio de configurações possíveis do sistema, gera-se entradas aleatoriamente usando uma certa distribuição de probabilidade sobre o domínio e, finalmente, executa-se uma computação determinística utilizando os dados de entradas. Essa última

\footnotetext{
${ }^{1}$ Mantivemos o nome de alguns jargões do algoritmo em inglês para facilitar a busca da literatura.

${ }^{2}$ Utilizamos unidades em que $\hbar=1$.
} 
deve obedecer a condição ergódica, i.e., todas as configurações possíveis do sistema devem poder ser geradas a partir desse mecanismo. Os resultados das computações individuais vão sendo agregados ao resultado final de modo que num tempo infinito a simulação convirja à solução exata. Contudo, se tivermos um conjunto grande e representativo de configurações, após um certo tempo de simulação estamos próximos o suficiente do resultado final. $\mathrm{O}$ erro estatístico pode ser reduzido com um aumento do tempo de simulação. Uma introdução elementar ao tema pode ser encontrada na referência [26].

O método de Monte Carlo baseia-se na geração de números aleatórios e, por mais contraditória que possa ser a ideia de criar números aleatórios, essa tornou-se uma ciência à parte. Em geral, usa operações aritméticas para a geração de uma sequência de números que denominamos números pseudo aleatórios, pois se parecem aleatórios embora não o sejam de fato, já que são determinados pelo algoritmo que os calculam. É de suma importância para o sucesso da simulação de Monte Carlo que estes sejam bons, ou seja, passem por alguns testes que avaliam se a sequência gerada está suficientemente próxima do que se espera de distribuições verdadeiramente aleatórias. Um dos geradores de números pseudo aleatórios mais simples é o linear congruential generator (LCG) [15]. Embora didático, não fornece uma sequência de números tão longa quanto o necessário em uma simulação de MC e há correlações entre os números. Usamos o gerador de números aleatórios RANMAR [27] modificado, que se mostrou adequado.

\subsection{Monte Carlo de integral de caminho}

É difícil resolver problemas de muitos corpos exatamente pois temos muitos graus de liberdade. O Monte Carlo resolve esse problema a custo de um erro estatístico que pode ser reduzido aumentando o tempo de simulação. $\mathrm{O}$ Monte Carlo de integral de caminho (cuja sigla em inglês é PIMC) mapeia o sistema quântico d-dimensional em um sistema clássico $(\mathrm{d}+1)$-dimensional, ou seja, executamos uma simulação clássica em uma dimensão a mais.

É útil escrever a hamiltoniana do sistema na forma $H=H_{0}+H_{1}$, em que $H_{0}$ é diagonal na base dos autoestados $|\alpha\rangle$ com autovalores $E_{\alpha}$

$$
H_{0}|\alpha\rangle=E_{\alpha}|\alpha\rangle,
$$

e $H_{1}$ é não-diagonal nesta base,

$$
H_{1}|\alpha\rangle=\sum_{\gamma} H_{1}^{\gamma \alpha}|\gamma\rangle ; \quad H_{1}^{\alpha \alpha}=0
$$


sendo que $H_{1}^{\gamma \alpha} \equiv\left\langle\gamma\left|H_{1}\right| \alpha\right\rangle$.

As propriedades de um sistema termodinâmico em equilíbrio a uma temperatura $T$ são determinadas pela função de partição $Z=\operatorname{Tr} e^{-\beta H}$, em que $\beta=1 / k_{B} T$, sendo $k_{B}$ a constante de Boltzmann. Observemos que se escrevermos o operador de evolução temporal $U(t)=e^{-i H t}$ em termos de um tempo imaginário $\beta=i$, este assume a forma da exponencial que determina a função de partição. Sua evolução em relação a $\beta$ é dada por

$$
\frac{d U}{d \beta}=-\left(H_{0}+H_{1}\right) U
$$

o que decorre da equação de Heisenberg que dá a evolução temporal de um operador.

Procuramos agora por uma solução da forma $U=e^{-\beta H_{0}} V$,

$$
\begin{aligned}
-H_{0} U+e^{-\beta H_{0}} \frac{d V}{d \beta} & =-H_{0} U-H_{1} e^{-\beta H_{0}} V \\
\frac{d V}{d \beta}=-e^{\beta H_{0}} H_{1} e^{-\beta H_{0}} V & \equiv-H_{1}(\beta) V,
\end{aligned}
$$

sendo que $H_{1}(\beta)=e^{\beta H_{0}} H_{1} e^{-\beta H_{0}}$. Logo,

$$
V=\mathcal{T}_{\tau} e^{-\int_{0}^{\beta} H_{1}(\tau) d \tau}
$$

sendo que introduzimos a variável de tempo imaginário $\tau$, definida no intervalo $0<\tau<\beta$. Como o operador $H_{1}(\tau)$ não comuta em intervalos tempos diferentes, fez-se necessário definir o chamado operador de tempo ordenado, $\mathcal{T}_{\tau}$, cuja função é ordenar temporalmente todos os $H_{1}(\tau)$, de maneira que estes operadores sejam escritos na ordem crescente de seus argumentos, da direita para a esquerda. Assim, mostramos que podemos reescrever o operador de evolução na forma

$$
U(\beta)=e^{-\beta H_{0}} \mathcal{T}_{\tau} e^{-\int_{0}^{\beta} H_{1}(\tau) d \tau},
$$

de maneira que passamos a trabalhar na chamada descrição de interação [21]. Nesta descrição os operadores evoluem no tempo como em uma descrição de Heisenberg, mas com relação apenas a parte diagonal $H_{0}$, i.e., $g^{(I)}(\beta)=U_{0}^{\dagger}(\beta) g(0) U_{0}(\beta)$, com $U_{0}(\beta)=e^{-\beta H_{0}}$. Já os autoestados evoluem como em uma descrição Schrödinger, $\left|\varphi^{(I)}(\beta)\right\rangle=U_{0}^{\dagger}(\beta) U(\beta)|\varphi(0)\rangle$ (note que a dependência é apenas em $H_{1}$ ). 
Ainda podemos expandir $\mathcal{T}_{\tau} e^{-\int_{0}^{\beta} H_{1}(\tau) d \tau}$ em uma série de Taylor para obter uma forma mais útil de (4.7). Sendo assim,

$$
\begin{aligned}
\mathcal{T}_{\tau} e^{-\int_{0}^{\beta} H_{1}(\tau) d \tau} & =1-\int_{0}^{\beta} H_{1}(\tau) d \tau+\frac{1}{2}\left[\left.\left(\int_{0}^{\beta} H_{1}\left(\tau_{1}\right) d \tau_{1} \int_{0}^{\beta} H_{1}\left(\tau_{2}\right) d \tau_{2}\right)\right|_{\tau_{1}>\tau_{2}}\right. \\
& \left.+\left.\left(\int_{0}^{\beta} H_{1}\left(\tau_{2}\right) d \tau_{2} \int_{0}^{\beta} H_{1}\left(\tau_{1}\right) d \tau_{1}\right)\right|_{\tau_{2}>\tau_{1}}\right]+\ldots \\
= & \sum_{n=0}^{\infty} \frac{(-1)^{n}}{n !} \int_{0}^{\beta} d \tau_{1} \int_{0}^{\beta} d \tau_{2} \ldots \int_{0}^{\beta} d \tau_{n} \mathcal{T}_{\tau}\left[H_{1}\left(\tau_{n}\right) \ldots H_{1}\left(\tau_{1}\right)\right] .
\end{aligned}
$$

Se ordenarmos explicitamente todas as integrais temporais, em cada conjunto desta temos $n$ ! termos iguais e este fator se cancela com o da expansão. E assim, podemos escrever a equação da seguinte forma:

$\mathcal{T}_{\tau} e^{-\int_{0}^{\beta} H_{1}(\tau) d \tau}=\sum_{n=0}^{\infty}(-1)^{n} \int_{0}^{\beta} d \tau_{n} \int_{0}^{\tau_{n}} d \tau_{n-1} \ldots \int_{0}^{\tau_{2}} d \tau_{1} H_{1}\left(\tau_{n}\right) \ldots H_{1}\left(\tau_{2}\right) H_{1}\left(\tau_{1}\right)$,

sendo que a condição de ordenação afeta os limites de integração.

Substituindo a expansão acima em $Z=\operatorname{Tr} e^{-\beta H}$, temos

$$
\begin{aligned}
Z & =\operatorname{Tr} e^{-\beta\left(H_{0}+H_{1}\right)}=\sum_{\alpha}\left\langle\alpha\left|e^{-\beta H_{0}} \mathcal{T}_{\tau} e^{-\int_{0}^{\beta} d \tau H_{1}(\tau)}\right| \alpha\right\rangle \\
& =\sum_{n=0}^{\infty}(-1)^{n} \int_{\tau_{1}<\tau_{2}<\cdots<\tau_{n}}^{\beta} d \tau_{1} d \tau_{2} \ldots d \tau_{n} \sum_{\alpha}\left\langle\alpha\left|e^{-\beta H_{0}} H_{1}\left(\tau_{n}\right) \ldots H_{1}\left(\tau_{2}\right) H_{1}\left(\tau_{1}\right)\right| \alpha\right\rangle,
\end{aligned}
$$

na qual utilizamos a seguinte notação:

$$
\int_{\tau_{1}<\tau_{2}<\cdots<\tau_{n}}^{\beta} d \tau_{1} d \tau_{2} \ldots d \tau_{n} \equiv \int_{0}^{\beta} \int_{0}^{\tau_{n}} \ldots \int_{0}^{\tau_{2}} d \tau_{1} d \tau_{2} \ldots d \tau_{n} .
$$

Fazendo uso da completeza da base $\{|\alpha\rangle\}$ e inserindo $n-1$ operadores iden- 
tidade $\mathbb{1}=\sum_{\alpha}|\alpha\rangle\langle\alpha|$ entre os produtos de $H_{1}\left(\tau_{n}\right)$, obtemos

$$
\begin{aligned}
& \left\langle\alpha\left|e^{-\beta H_{0}} H_{1}\left(\tau_{n}\right) \ldots H_{1}\left(\tau_{1}\right)\right| \alpha\right\rangle= \\
& \quad=e^{-\beta E_{\alpha}} \sum_{\alpha_{1} \ldots \alpha_{n-1}} H_{1}^{\alpha \alpha_{n-1}}\left(\tau_{n}\right) \ldots H_{1}^{\alpha_{2} \alpha_{1}}\left(\tau_{2}\right) H_{1}^{\alpha_{1} \alpha}\left(\tau_{1}\right),
\end{aligned}
$$

com os elementos de matriz sendo

$$
H_{1}^{\alpha^{\prime} \alpha}(\tau)=e^{\tau E_{\alpha^{\prime}}} H_{1}^{\alpha^{\prime} \alpha} e^{-\tau E_{\alpha}}=\left\langle\alpha^{\prime}\left|H_{1}\right| \alpha\right\rangle e^{-\tau\left(E_{\alpha}-E_{\alpha^{\prime}}\right)} .
$$

Note que, sendo a função de partição $Z$ definida por um traço, temos a condição de que cada elemento de matriz da soma em (4.13) deve iniciar e terminar no estado $|\alpha\rangle$.

Finalmente, inserindo a expressão (4.13) em (4.11), obtemos

$$
\begin{aligned}
Z=\sum_{n=0}^{\infty}(-1)^{n} & \int_{\tau_{1}<\tau_{2}<\cdots<\tau_{n}}^{\beta} d \tau_{1} \ldots d \tau_{n} \times \\
& \times \sum_{\alpha, \alpha_{1} \ldots \alpha_{n-1}} e^{-\beta E_{\alpha}} H_{1}^{\alpha \alpha_{n-1}}\left(\tau_{n}\right) \ldots H_{1}^{\alpha_{2} \alpha_{1}}\left(\tau_{2}\right) H_{1}^{\alpha_{1} \alpha}\left(\tau_{1}\right) .
\end{aligned}
$$

Essa expressão para a função de partição encontra-se no seu formato final e está na chamada representação de integrais de caminho [15]. Podemos construir diagramas que representam configurações do sistema a partir dessa equação. Para entender como construir tais diagramas, reescrevemos (4.11) explicitando a dependência temporal e colocando os estados que definem o traço no formalismo da segunda quantização, isto é $|\alpha\rangle=\left|\left\{n_{i}\right\}\right\rangle \equiv$ $\left|\left\{n_{1}, n_{2}, \ldots\right\}\right\rangle$, na forma como segue: 


$$
\begin{gathered}
Z=\sum_{\left\{n_{i}\right\}}\left\langle\left\{n_{i}\right\}\right| e^{-\beta H_{0}}-\int_{0}^{\beta} d \tau_{1} e^{-\left(\beta-\tau_{1}\right) H_{0}} H_{1} e^{-\left(\tau_{1}-0\right) H_{0}}+ \\
+\int_{0}^{\beta} \int_{0}^{\tau_{2}} d \tau_{1} d \tau_{2} e^{-\left(\beta-\tau_{2}\right) H_{0}} H_{1} e^{-\left(\tau_{2}-\tau_{1}\right) H_{0}} H_{1} e^{-\left(\tau_{1}-0\right) H_{0}}+\cdots+ \\
+\int_{0}^{\beta} \int_{0}^{\tau_{k}} \ldots \int_{0}^{\tau_{2}} d \tau_{1} \ldots d \tau_{k-1} d \tau_{k} \quad \times \\
\times e^{-\left(\beta-\tau_{k}\right) H_{0}} H_{1} e^{-\left(\tau_{k}-\tau_{k-1}\right) H_{0}} H_{1} e^{-\left(\tau_{k-1}-\tau_{k-2}\right) H_{0}} \ldots e^{-\left(\tau_{2}-\tau_{1}\right) H_{0}} H_{1} e^{-\left(\tau_{1}-0\right) H_{0}}+ \\
+\left|\left\{n_{i}\right\}\right\rangle \cdot \quad(4.16)
\end{gathered}
$$

Nessa equação, o estado inicial $\left|\left\{n_{i}\right\}\right\rangle$ passa por sucessivos operadores de evolução temporal no tempo imaginário, em que os números de ocupação se modificam pela ação de $H_{1}$. Assim, no primeiro termo, o estado inicial permanece o mesmo no intervalo de 0 a $\beta$, o segundo termo é zero, pois $H_{1}$ é não-diagonal na base $\{\alpha\}$, já o terceiro termo, evolui o estado inicial ao longo de três intervalos de tempo diferentes: 0 a $\tau_{1}, \tau_{1}$ a $\tau_{2}$ e $\tau_{2}$ a $\beta$, modificando os números de ocupação de $\left|\left\{n_{i}\right\}\right\rangle_{\tau=0}$ para $H_{1}\left|\left\{n_{i}\right\}\right\rangle_{\tau=\tau_{1}}=\left|\left\{n_{i}\right\}^{\prime}\right\rangle_{\tau=\tau_{1}}$ e para $H_{1}\left|\left\{n_{i}\right\}^{\prime}\right\rangle_{\tau=\tau_{2}}=\left|\left\{n_{i}\right\}^{\prime \prime}\right\rangle_{\tau=\tau_{2}}$ e permanecendo ali até que $\tau=\beta$. Este último termo será não-nulo apenas se retornar a configuração inicial, isto é, $\left\{n_{i}\right\}^{\prime \prime}=\left\{n_{i}\right\}$. E assim por diante.

Cada sequência $\alpha=\left\{n_{i}\right\}, \alpha_{1}=\left\{n_{i}\right\}_{1}, \alpha_{2}=\left\{n_{i}\right\}_{2}, \ldots, \alpha_{n-1}=\left\{n_{i}\right\}_{n-1} \equiv$ $\alpha(\tau)$ é uma trajetória no espaço- $\alpha$. Tendo em vista que a evolução temporal nos leva de volta ao estado inicial, i.e. $\alpha_{0}=\alpha_{n}$, teremos caminhos fechados $(\mathrm{CF})$ e, por consequência, temos condições periódicas de contorno para o tempo imaginário. Dessa forma, $Z$ é a soma de todas as trajetórias $\mathrm{CF}$ possíveis.

Esta formulação será utilizada para estimar os observáveis a partir da função de partição. E desse ponto, por meio de técnicas padrões do método Monte Carlo, podemos simular o sistema. 


\subsubsection{Integral de caminho para o modelo de Bose-Hubbard}

Considere novamente a hamiltoniana de Bose-Hubbard (2.25), que reescrevemos aqui por conveniência:

$$
H=-J \sum_{\langle i, j\rangle} b_{i}^{\dagger} b_{j}+\frac{U}{2} \sum_{i} \hat{n}_{i}\left(\hat{n}_{i}-1\right)-\mu \sum_{i} \hat{n}_{i},
$$

e lembre-se de que estamos descrevendo um sistema 2D de bósons sem spin em uma rede ótica de tamanho $L \times L$, com interação intra-sítio e tunelamento apenas entre primeiros vizinhos. Dessa forma, podemos passar esse sistema para o formalismo de integral de caminho fazendo a identificação

$$
\begin{aligned}
H_{0} & =\frac{U}{2} \sum_{i} \hat{n}_{i}\left(\hat{n}_{i}-1\right)-\mu \sum_{i} \hat{n}_{i}, \\
H_{1} & =-J \sum_{\langle i, j\rangle} b_{i}^{\dagger} b_{j} .
\end{aligned}
$$

Continuando a trabalhar na base dos termos de interação $H_{0}$ no formalismo da segunda quantização, temos $|\alpha\rangle=\prod_{i=1}^{L^{2}}\left|n_{i}\right\rangle$. Os autovalores da hamiltoniana diagonal neste caso são

$$
E_{\alpha}=\frac{U}{2} \sum_{i} n_{i}\left(n_{i}-1\right)-\mu \sum_{i} n_{i}
$$

enquanto os não-diagonais são

$$
H_{1}^{\alpha^{\prime} \alpha}=-J\left\langle n_{i}+1, n_{j}-1\left|b_{i}^{\dagger} b_{j}\right| n_{i}, n_{j}\right\rangle=-J \sqrt{n_{i}^{\alpha}\left(n_{j}^{\alpha}+1\right)} .
$$

com $i$ e $j$ denotando sítios vizinhos e $n_{i}^{\alpha}$, o número de partículas no sítio $i$ no estado inicial $|\alpha\rangle$. Incluindo esses valores em (4.15) obtemos a função de partição a ser usada na simulação

$$
\begin{array}{r}
Z_{B H}=\sum_{n=0}^{\infty} \int_{0}^{\beta} \ldots \int_{0}^{\tau_{2}} d \tau_{1} \ldots d \tau_{n} \sum_{\alpha_{0} \alpha_{1} \ldots \alpha_{n-1}}(-1)^{n} H_{1}^{\alpha_{n} \alpha_{n-1}} \ldots H_{1}^{\alpha_{1} \alpha_{0}} \times \\
\times \exp \left\{-\beta E_{\alpha_{0}}-\sum_{m=0}^{n-1} E_{\alpha_{m}}\left(\tau_{m+1}-\tau_{m}\right)\right\},
\end{array}
$$

sendo que utilizamos (4.14) e, para manter a escrita compacta, definimos $\alpha_{0}=\alpha_{n}=\alpha$ e $\tau_{n}=\tau_{0}$. 
Porém, será mais conveniente no cálculo dos observáveis reescrever o expoente da exponencial de outra forma. Voltando a escrever $\tau_{0}=\tau_{n}$, somando $E_{\alpha_{0}} \tau_{0}$ (com $\left.\tau_{0}=0\right)$ e considerando $\beta=\tau_{n+1}$ podemos reordenar os termos de maneira que obtemos

$$
\begin{aligned}
& -\beta E_{\alpha_{0}}-\sum_{m=0}^{n-1} E_{\alpha_{m}}\left(\tau_{m+1}-\tau_{m}\right)=-E_{\alpha_{0}}\left(\tau_{1}-\tau_{0}\right)-E_{\alpha_{1}}\left(\tau_{2}-\tau_{1}\right)- \\
& -\ldots-E_{\alpha_{n-1}}\left(\tau_{n}-\tau_{n-1}\right)-E_{\alpha_{n}}\left(\tau_{n+1}-\tau_{n}\right)=-\sum_{m=0}^{n} E_{\alpha_{m}}\left(\tau_{m+1}-\tau_{m}\right) .
\end{aligned}
$$

Assim, escrevendo explicitamente a dependência da configuração do sistema com o tempo imaginário como $\alpha=\alpha(\tau)$, podemos reescrever

$$
\begin{aligned}
Z_{B H} & =\sum_{n=0}^{\infty} \int_{0}^{\beta} \ldots \int_{0}^{\tau_{2}} d \tau_{1} \ldots d \tau_{n} \sum_{\alpha_{0} \alpha_{1} \ldots \alpha_{n-1}}(-1)^{n} H_{1}^{\alpha_{n} \alpha_{n-1}} \ldots H_{1}^{\alpha_{1} \alpha_{0}} \times \\
& \times \exp \left\{-\sum_{m=0}^{n} \int_{\tau_{m}}^{\tau_{m+1}} E_{\alpha_{m}(\tau)} d \tau\right\} .
\end{aligned}
$$

O que também pode ser escrito como

$$
Z_{B H}=\sum_{\nu} W_{\nu}
$$

sendo $W_{\nu}$ o peso estatístico de cada configuração $\nu=\left\{n, \alpha_{0} \alpha_{1} \ldots \alpha_{n-1}\right\}$ (note que é um CF).

Podemos entender melhor o que isso significa através da figura 4.1 onde temos uma configuração desenhada para uma rede 2D. O eixo y desse esquema é o tempo imaginário e o eixo $x$ representa os sítios do sistema. Lembrando que o tempo obedece condições periódicas de contorno, ou seja, podemos ligar os dois extremos dessas linhas formando um toróide. Cada linha é usualmente conhecida como linha-mundo (em inglês worldline) e representa um único sítio do sistema. O número de partículas deste sítio é proporcional a largura de cada linha.

Sendo assim, o espaço de configurações do sistema é representado por uma coleção de caminhos fechados (CF), onde é permitido interseções, laços múltiplos e sobreposições, a única restrição é que não haja finais abertos. 
Deste modo, podemos criar caminhos de tamanhos arbitrários mudando o número de laços. Chamaremos de kinks pontos no tempo em que o sistema muda de estado (por exemplo, $\tau_{k}$ na figura). Tendo em mente a equação (4.16), associamos cada kink à ação dos operadores $H_{1}$ e cada intervalo contínuo do caminho com a ação do operador de evolução temporal $e^{-\tau H_{0}}$. Procedimentos de atualização neste sistema consistem em deslocar kinks e criar novos a partir de uma região sem kinks.

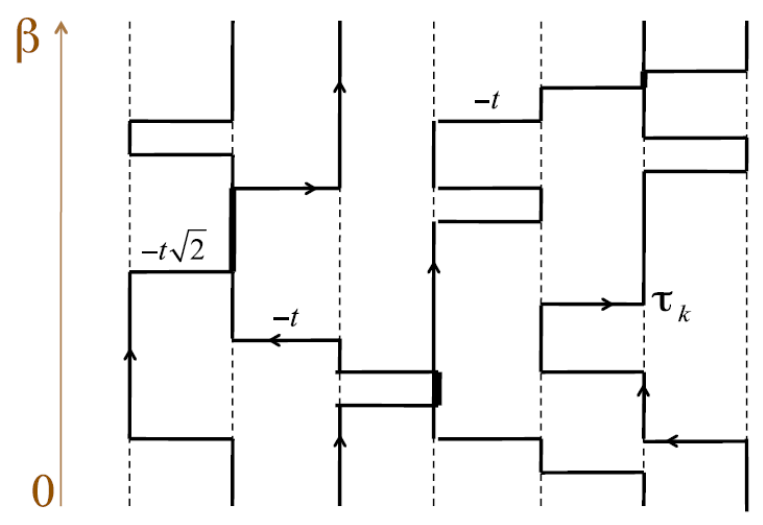

Figura 4.1: Espaço de configuração de caminhos fechados (CF). As linhasmundo ou worldlines representam sítios com um número de ocupação proporcional a sua espessura. As linhas tracejadas tem ocupação zero, as sólidas que são mais finas, possuem ocupação um e as mais grossas, ocupação dois. A evolução do tempo imaginário está representada à esquerda. Nesta imagem, $t$ é o peso de um kink e é equivalente ao $J$ em nossa notação. (Figura da referência [28].)

\section{Cálculo dos observáveis}

Para construir o diagrama de fases do sistema utilizamos apenas um observável: o valor médio de partículas do sistema $\langle N\rangle$. Este pode ser estimado a partir de $Z$. Utilizando a equação (4.22) com uma notação mais 
conveniente,

$$
\begin{aligned}
Z_{B H}=\sum_{\nu} W_{\nu} & =\sum_{n=0}^{\infty} \sum_{\left\{n_{i}\right\}} \int_{0}^{\beta} \int_{0}^{\tau_{n}} \ldots \int_{0}^{\tau_{2}} d \tau_{1} \ldots d \tau_{n} \times \\
\times & \prod_{k=1}^{n}\left\langle\left\{n_{i}\right\}_{\tau_{k}}\left|-H_{1}\right|\left\{n_{i}\right\}_{\tau_{(k-1)}}\right\rangle e^{-\int_{0}^{\beta} E\left[\left\{n_{i}\right\}_{\tau}\right] d \tau},
\end{aligned}
$$

sendo que escrevemos os estados $|\alpha\rangle$ em termo de números de ocupação e explicitamos a dependência com o tempo acrescentando o índice $\tau$ em $\left\{n_{i}\right\}_{\tau}$. Podemos então estimar esse observável a partir desta equação fazendo a transformação de variável $d \tau \rightarrow \beta d s$,

$$
\langle N\rangle=T \frac{d \ln Z_{B H}}{d \mu}=Z^{-1} \sum_{\nu} W_{\nu} \int_{0}^{1} \sum_{i} n_{i}(s) d s=\left\langle\sum_{i} n_{i}\right\rangle,
$$

em que utilizamos (4.18), sendo $T$ a temperatura e $\mu$ o potencial químico. Outros observáveis como a energia e a compressibilidade também podem ser estimados a partir da função de partição [28].

\subsection{O algoritmo Worm}

O algoritmo Worm foi originalmente introduzido para modelos quânticos estatísticos por N. V. Prokof'ev, B. V. Svistunov e I. S. Tupitsyn [14] e depois generalizado para modelos clássicos por N. V. Prokof'ev e B. V. Svistunov [15]. Para uma introdução ao algoritmo, é bastante instrutivo estudá-lo aplicado ao modelo de Ising, cujos detalhes são encontrados nas notas [15]. Na referência [29] podemos encontrar o fundamento teórico para a representação utilizada neste caso.

Este algoritmo trabalha num espaço de configurações aumentado (ver fig. 4.2), onde acumulamos estatísticas também com caminhos abertos, i.e., trajetórias em que $\alpha_{0} \neq \alpha_{n}$, que denotaremos por $\mathrm{CF}_{g}$. Pode-se mostrar que estas estatísticas contribuem para o cálculo da função de Green de Matsubara [30] e outros observáveis do sistema são obtidos a partir dessa função:

$$
G(j, \tau)=\left\langle\mathcal{T}_{\tau} b_{i+j}\left(\tau_{0}+\tau\right) b_{i}^{\dagger}\left(\tau_{0}\right)\right\rangle,
$$

sendo $\mathcal{T}_{\tau}$ o operador de ordenação temporal. A interpretação do operador $b_{i}^{\dagger}\left(\tau_{0}\right)$, por definição, é a criação de uma partícula no sítio $i$ no tempo imaginário $\tau_{0}$, cujo autovalor é $\sqrt{n_{i}\left(\tau_{0}\right)+1}$, e a de $b_{i+j}\left(\tau_{0}+\tau\right)$, é a aniquilação 
de uma partícula no sítio $i+j$ no tempo $\tau_{0}+\tau$ com autovalor $\sqrt{n_{i+j}\left(\tau_{0}+\tau\right)}$. Por razões históricas os operadores $b$ e $b^{\dagger}$ são denominados, respectivamente de ira e masha ${ }^{3}$.

Os mecanismos de atualização do algoritmo são locais e feitos a partir de uma configuração $\mathrm{CF}_{g}$ ou $\mathrm{CF}$ (ver figura 4.2). Quando o sistema está em uma certa configuração $\nu$ o algoritmo deve gerar aleatoriamente uma nova configuração $\nu^{\prime}$ e coletar estatísticas para o cálculo dos observáveis de interesse. A ergodicidade é garantida apenas se esses mecanismos forem totalmente aleatórios.

Assim, pictoricamente podemos ver essas atualizações como sendo feitas por mecanismos de "desenha" e "apaga", onde conseguimos construir diferentes laços a partir dos extremos de um $\mathrm{CF}_{g}$, motivando o nome Worm ("verme", em inglês) atribuído ao algoritmo. Denominamos um caminho $\mathrm{CF}_{g}$ de verme, sendo suas extremidades denominadas ira (b, a cabeça do verme) e masha ( $b^{\dagger}$, a cauda). Sendo assim, a medida que o verme se movimenta no espaço de configurações, modifica as configurações $\mathrm{CF}_{g}$ e acumula estatísticas para G. As atualizações das CF são feitas quando, de tempos em tempos, os dois extremos do $\mathrm{CF}_{g}$ se encontram e assim recuperamos uma configuração-CF e coletamos estatísticas para $Z$.

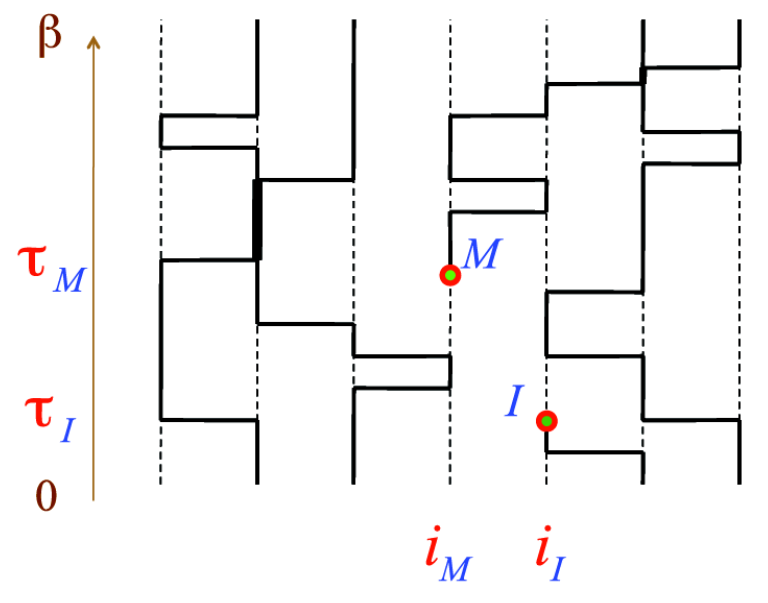

Figura 4.2: Espaço de configurações de caminhos abertos $\left(\mathrm{CF}_{g}\right)$. Os pontos indicados por $I$ e $M$ na figura são respectivamente, ira e masha, os extremos do verme. (Imagem extraída da referência [28].)

A partir de uma configuração $\nu$ o algoritmo seleciona aleatoriamente um

\footnotetext{
${ }^{3}$ são os nomes das irmãs de B. V. Svistunov e implicitamente inteiros em Fortran [15].
} 
intervalo da configuração no tempo imaginário de algum sítio e podem ocorrer quatro tipos de atualizações que serão descritas a seguir. Vale ressatar que essas atualizações são locais, no sentido que mudam apenas variáveis ao redor de um ponto deixando o resto da configuração intacta, e também que o algoritmo trabalha no ensemble grande canônico, uma vez que a movimentação do verme no espaço de configurações do sistema muda o número de partículas dos sítios.

\subsubsection{Criação e destruição do verme}

A única atualização feita no espaço CF é a criação de um verme. Um intervalo $\tau_{\max }$ a $\tau_{\min }$ com número de ocupação $n_{1}$ (ver figura 4.3), é aleatoriamente selecionado em uma linha-mundo também aleatória. Então dois pontos deste intervalo, por exempo $\tau_{1}$ e $\tau_{2}$, são selecionados aleatoriamente, estes pontos serão as extremidades do verme (ira e masha). Com probabilidades iguais, sugerimos desenhar ou apagar um pedaço da linha-mundo entre ira e masha (i.e., criar ou destruir uma partícula naquele intervalo de tempo), com a restrição de que não é possível apagar um intervalo vazio ou desenhar em um intervalo que atingiu um número de ocupação máxima, se houver algum. Com o verme criado, outras atualizações irão ocorrer a partir dos seus extremos. A atualização oposta, a destruição do verme, onde o par ira-masha é apagado, só pode ocorrer no espaço $\mathrm{CF}_{g}$ e apenas se as duas extremidades do verme pertencerem à mesma linha-mundo. Esta também ocorre com uma certa probabilidade e depois disso, o sistema passa para o espaço CF. 


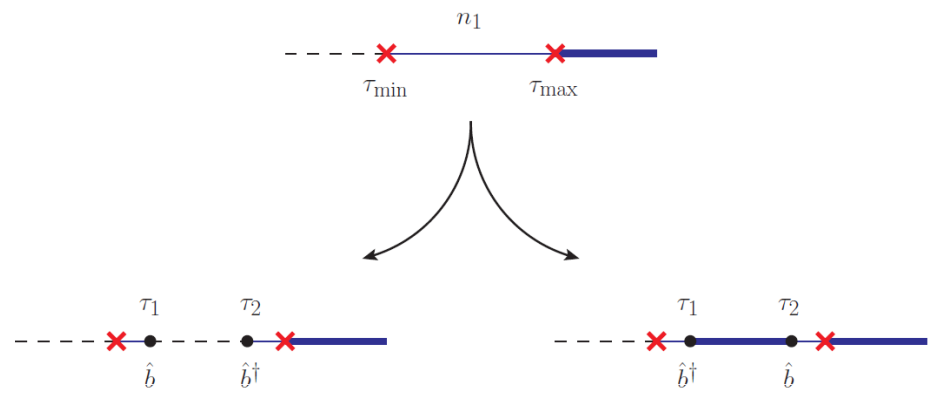

Figura 4.3: Criação de um verme em uma linha-mundo, onde passamos de um espaço $\mathrm{CF}$ para um $\mathrm{CF}_{g}$. Na figura, $b$ é ira, a cabeça do verme, e $b^{\dagger}$ é masha, a cauda. Após selecionar aleatoriamente um intervalo $\tau_{\max }-$ $\tau_{\text {min }}$, ocorre a criação do par ira-masha nos pontos $\tau_{1}$ e $\tau_{2}$ aleatoriamente selecionados neste intervalo. À esquerda, a criação do verme apaga um pedaço da linha-mundo e à direita desenha. (Imagem extraída da referência [30].)

\subsubsection{Movimentação temporal}

É a atualização mais simples e consiste em mover uma das extremidades do verme na mesma linha-mundo até um ponto aleatório do tempo imaginário, diminuindo ou aumentando o tamanho do verme e mudando o número de ocupação do sítio neste intervalo de tempo. O programa seleciona aleatoriamente um intervalo de tempo delimitado por $\tau_{\min }$ e $\tau_{\max }$ (ver figura 4.4) e neste um ponto aleatório $\tau^{\prime}$ é selecionado e a cabeça ou a cauda do verme é deslocada até este ponto.

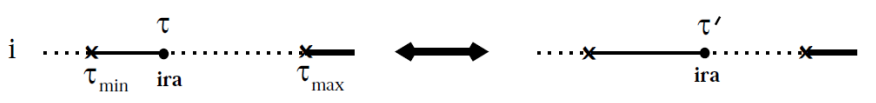

Figura 4.4: Movimentação temporal do verme, i.e., sem mudar de sítio. (Imagem extraída da referência [15].)

\subsubsection{Movimentação espacial}

Nesse procedimento sugerimos criar ou deletar um kink à esquerda ou à direita da ira ou da masha, mudando o número de kinks da configuração. 
Duas linhas-mundo vizinhas são escolhidas aleatoriamente, por exemplo $i$ e $j$ da figura 4.5, então, baseado na posição do operador $b$, o programa escolhe aleatoriamente um intervalo de tempo delimitado por $\tau_{\min }$ e $\tau_{\max }$. Dentro deste intervalo, é selecionado aleatoriamente um ponto onde irá se criar ou remover um kink com a condição de que o kink criado ou removido não interfira em nenhum outro já existente. Na figura 4.5, (a) cria um kink à esquerda, isto é, para trás no tempo e $(b)$ à direita, para frente no tempo. Note que um kink muda o número de ocupação de dois sítios.

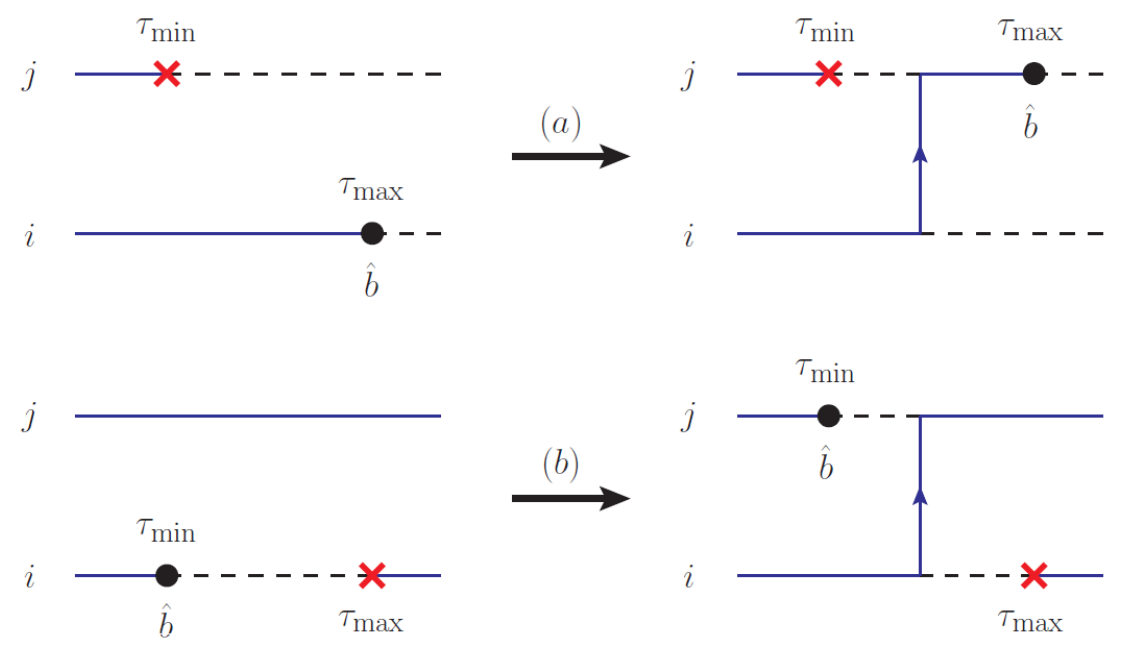

Figura 4.5: Movimenta o verme espacialmente aumentando ou diminuindo o número de kinks. Na figura (a), a movimentação espacial à esquerda cria um kink para trás no tempo imaginário, e na figura (b), a movimentação espacial à direta cria um kink para frente no tempo. (Imagem extraída da referência [30].)

Para exemplificar as atualizações do espaço de configurações segue na figura 4.6 uma sequência de movimentos possíveis do verme a partir de um espaço de configuração. Um diagrama de fluxos do algoritmo segue nas figuras 4.7 e 4.8, sendo a segunda figura um detalhamento da primeira. 

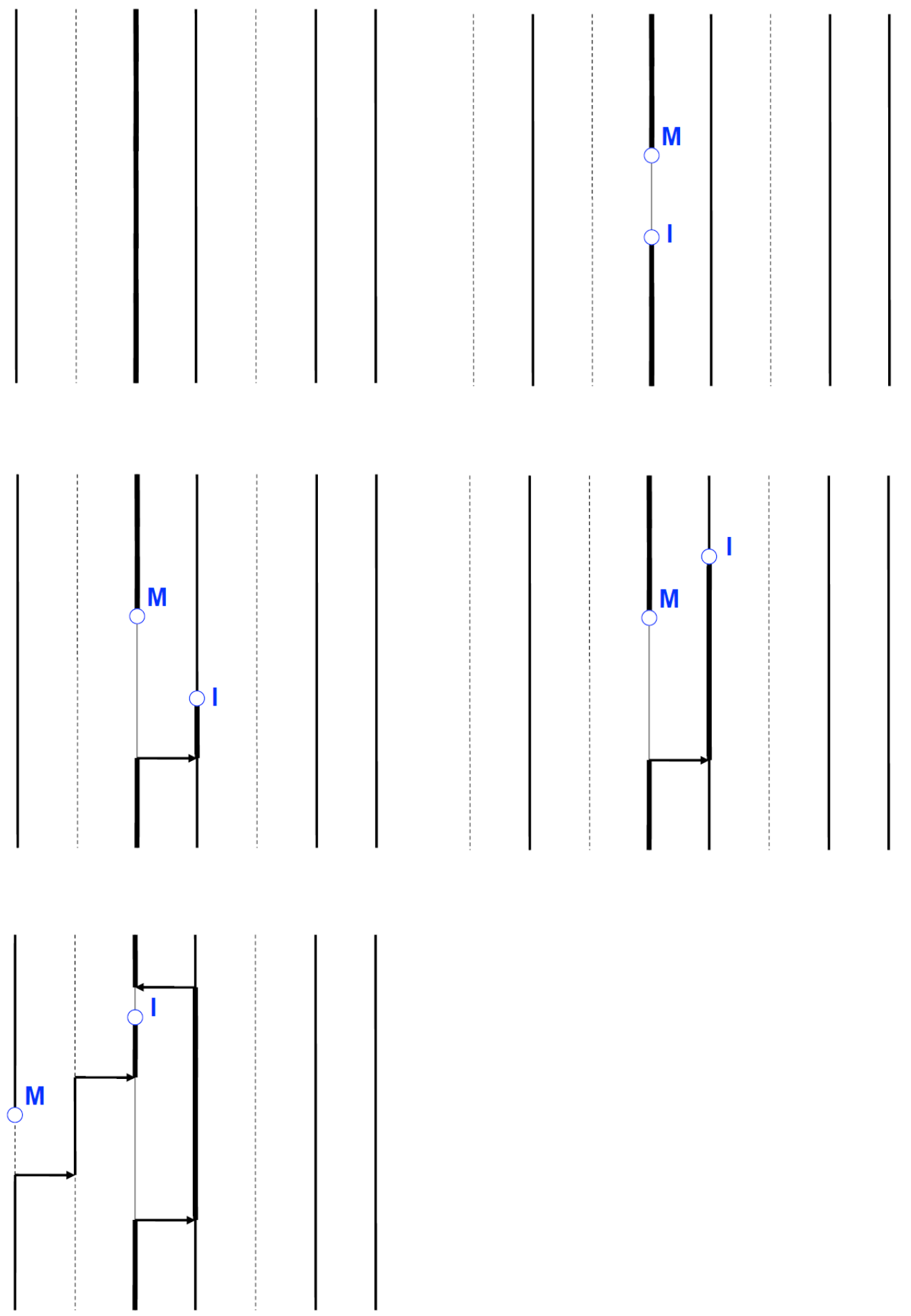

Figura 4.6: A primeira figura é uma configuração inicial qualquer do sistema, em seguida o verme é criado em um sítio aleatório (sendo I ira e M macha). Na sequência, ira realiza um kink, logo depois se movimenta temporalmente e após um certo tempo de simulação chegamos a uma configuração qualquer (última figura).(Imagem extraída da referência [28].) 


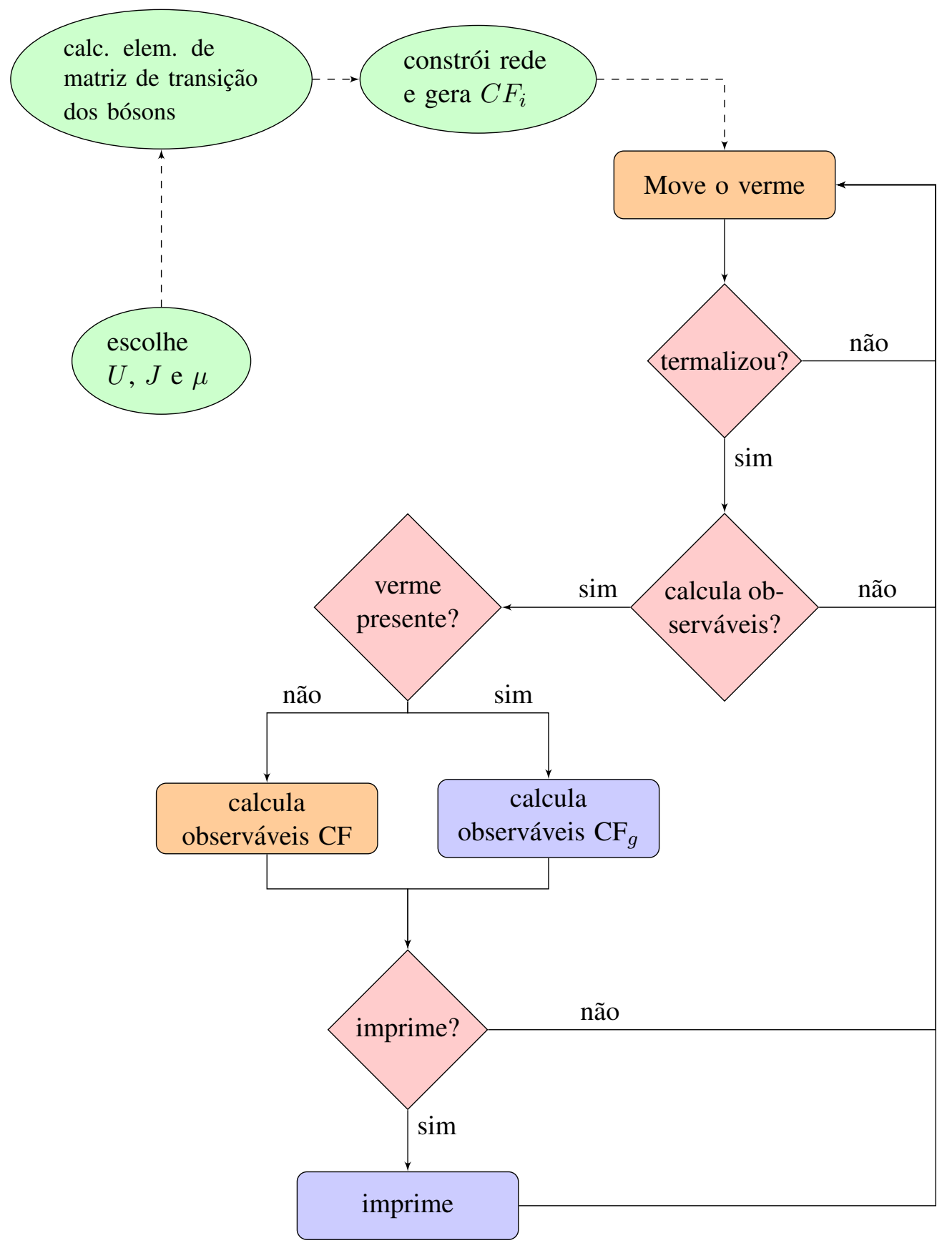

Figura 4.7: Fluxograma do algoritmo Worm. Sendo que a configuração inicial $\mathrm{CF}_{i}$ que utilizamos é de uma partícula por sítio, correspondendo a um conjunto de linhas com a mesma espessura (equivalente a um átomo) e sem kinks. Os blocos em laranja foram expandidos na figura seguinte, 4.8. 

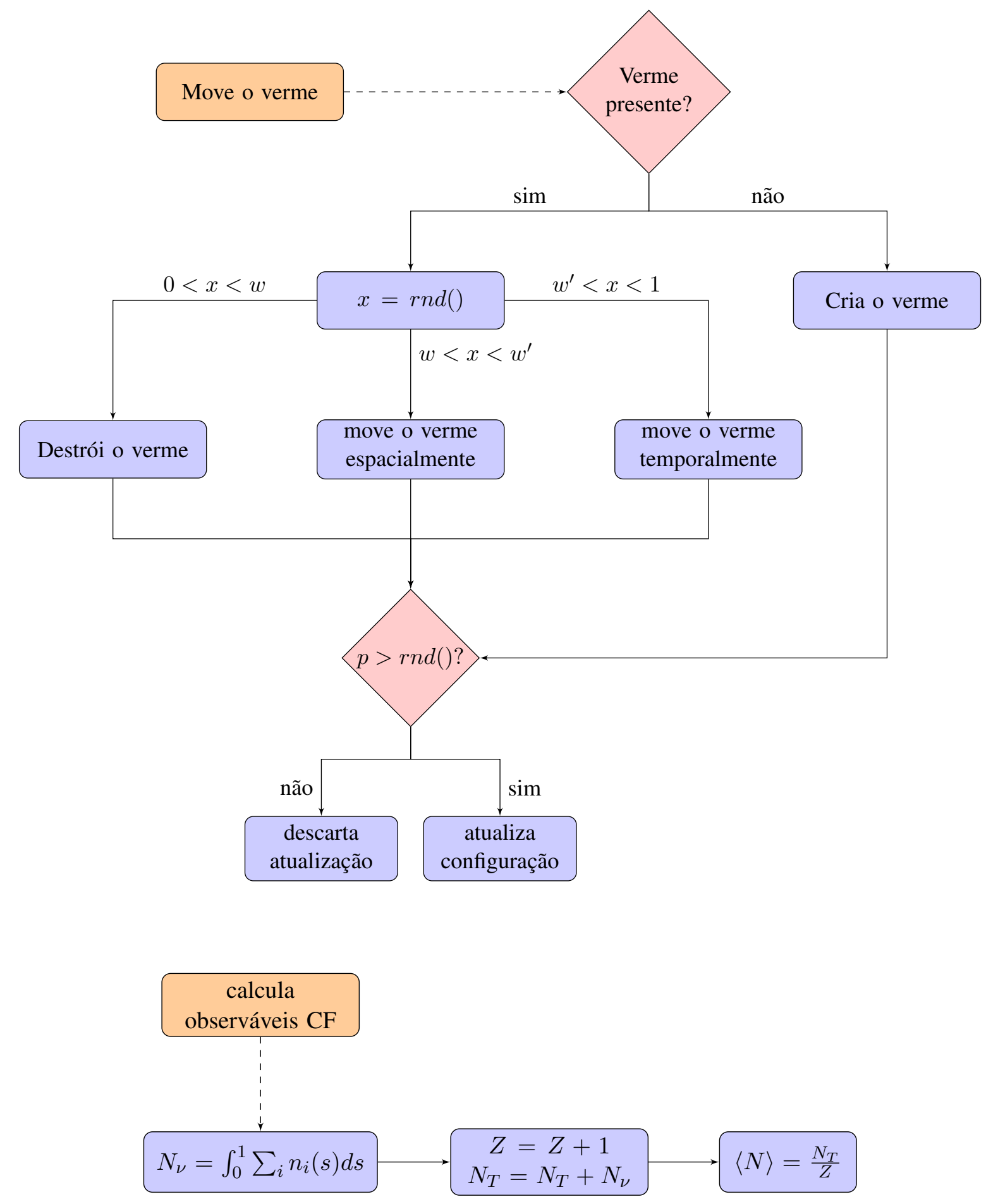

Figura 4.8: No primeiro fluxograma detalhamos o bloco "move verme". Sendo que $r n d()$ representa um gerador de números aleatórios, $w$ e $w^{\prime}$ são as probabilidades de um dos movimentos do verme aconter e $p$ é a probabilidade de aceite de um movimento e é diferente para cada movimento, mas para simplificar o diagrama condensamos essa informação. No segundo fluxograma, detalhamos o bloco "calcula obeserváveis CF" para o observável utilizado neste trabalho, $\langle N\rangle$. Sendo $N_{\nu}$ o número de partículas da configuração $\nu$ em que o sistema se encontra, $Z$ é um contador do número de caminho fechados e $N_{T}$ guarda os valores de $N_{\nu}$. 


\subsubsection{Considerações}

Veremos mais adiante no capítulo 5, que a utilização do algoritmo Worm para o estudo da transição de Mott responde bem aos propósitos do nosso estudo. Para uma discussão mais detalhada das vantagens e desvantagens do Worm frente aos demais algoritmos, sugerimos às referências [14, 15, 30, 28]. Aqui nos limitamos a reescrever algumas considerações relevantes sobre o assunto.

A maioria dos códigos de MC apresentam problemas tais como trabalhar com um número fixo de partículas (ensemble canônico), desaceleração crítica (critical slowing down), acumulação lenta de estatísticas para a função de Green, entre outros [14]. Como vimos, o algoritmo Worm trabalha no ensemble grande canônico e tem o seu espaço de configurações aumentado usando $\mathrm{CF}+\mathrm{CF}_{g}$. É claro, isso traz vantagens.

Um ponto importante de se mencionar é que sendo as atualizações locais e o peso das configurações $W_{\nu}$ fatorável, a equação de balanço que determina as probabilidades de aceitação e rejeição de uma atualização é muito simplificada [15, 28]. Sendo assim, podemos desenhar ou apagar qualquer linha e pular entre sítios facilmente e, portanto, não há problemas em produzir laços a partir de outros com condições de contorno periódicas. Por isso, o algoritmo é eficiente em criar configurações topologicamente diferentes e que são separadas por uma barreira de energia, o que é uma condição necessária para manter a ergodicidade.

O algoritmo Worm não é afetado pelo critical slowing down. Na região crítica, sistemas como o estudado aqui desenvolvem correlações de longo alcance e a maioria dos algoritmos baseados em atualizações locais são ineficientes em simular tais sistemas em que os graus de liberdade relevantes são não-locais, afetando a precisão dos dados. O Worm, mesmo fazendo atualizações locais, acumula estatísticas para a função de Green eficientemente e esta pode ser utilizada para calcular as correlações no sistema, e assim podemos contornar este problema [30].

As configurações CF contribuem com o cálculo da função de partição. Tendo em vista que o algoritmo também coleta estatísticas com as configurações $\mathrm{CF}_{g}$ para a função de Green, podemos calcular outros observáveis tais como a fração de superfluido, a fração do condensado e a distribuição do momento [28].

No nosso caso, foi suficiente utilizar apenas as configurações CF, pois o único observável utilizado na construção do diagrama de fases da transição de Mott é estimado utilizando $Z$. No entanto, como mencionado, outras informações desse modelo podem ser obtidas utilizando $G$, que é estimada 
pelo algoritmo fazendo uso das configurações $\mathrm{CF}_{g}$. Não houve tempo para estender nosso estudo com essa perspectiva, faz parte de nossas pretenções de continuação, inclusive a de continuar estudando o algoritmo. Destacamos, no entando, que esse algoritmo não simula a evolução temporal do sistema. De fato, não sabemos se isso é possível, conseguimos apenas obter o seu estado fundamental. 


\section{Capítulo 5}

\section{Resultados numéricos: o diagrama de fases com o algoritmo Worm}

Os resultados obtidos com simulações numéricas utilizando o algoritmo Worm estão listados aqui. Guiados pelo diagrama feito no capítulo 3 construiremos um diagrama de fases utilizando o algoritmo Worm para o cálculo de observáveis. Para isso faremos um estudo simplificado da influência da temperatura e do tamanho da rede no diagrama. Obteremos um diagrama de fases do modelo de Bose-Hubbard homogêneo bidimensional, o compararemos com a teoria de campo médio anteriormente desenvolvida e com a literatura encontrada.

\subsection{Diagrama de fases II: ajustes e refinamentos}

Assim como feito na análise de campo médio no capítulo 3, vamos construir o diagrama de fases (DF) da transição SF-MI utilizando agora o método de Monte Carlo Quântico estudado no capítulo anterior. Como já discutimos, o diagrama de fases dessa transição corresponde ao plano $(J / U, \mu / U)$ em que a fronteira entre as fases SF e MI é desenhada.

Novamente, utilizaremos apenas um observável para diferenciar as duas fases, o fator de preenchimento, que é inteiro na fase Mott e não-inteiro na fase SF. A fronteira entre as fases é delimitada da forma que segue. Partindo de um estado com densidade comensurável inteira, com um dado valor da razão entre o potencial químico e a interação intra-sítio $\mu / U$ e da razão entre a intensidade de tunelamento e a interação intra-sítio $J / U$, variamos apenas 
$J / U$ e calculando a densidade por sítio do sistema $\rho=\langle N\rangle / L^{2}$ (veja equação (4.25)) a cada novo ponto $(J / U, \mu / U)$, sendo $L$ o tamanho linear da rede. Definimos o valor do ponto de transição como sendo o valor $(J / U, \mu / U)$ em que a densidade deixa de ser um valor inteiro. A fronteira entre as fases dessa transição é então definida a partir do conhecimento dos pontos de transição para diferentes valores do potencial químico, e assim construímos o diagrama de fases.

Para tanto, temos que estabelecer alguns critérios para a construção do diagrama como a discretização do $J / U$ e de $\mu / U$, e um critério para determinar se o fator de preenchimento é ainda inteiro, como será discutido na próxima subseção. Também estudaremos a influência da temperatura e do tamanho da grade no diagrama.

\subsubsection{Critérios}

Vemos ilustrada na figura 5.1 a mudança de comportamento da densidade por sítio tal qual descrito acima. O ponto de transição será tão mais bem definido quanto menor for o passo dado na varredura nos valores de $J / U$. Da mesma forma, a definição do desenho da fronteira entre as fases dependerá do tamanho do passo dado na variação do potencial químico.

De acordo com o propósito, escolhemos diferentes discretizações para essas variáveis, já que o problema exige um certo tempo computacional e nem sempre uma discretização apurada traz mais informações relevantes. Ao longo do trabalho usamos dois conjuntos de discretização: um pouco discretizado, em que o passo de $\mu / U$ é 0.0422 e o de $J / U$ é 0.00211 , e outro mais discretizado, com o passo de $\mu / U$ igual a 0.0211 ou 0.0105 e de $J / U$ igual a $0.000132^{1}$. O erro no ponto de transição devido à discretização escolhida em $J / U$ é, no caso primeiro caso, 0.001 e, no segundo, 0.00007 .

Para identificar a região do isolante de Mott, temos que definir um critério que estabelece quando a densidade passa a ser não-inteira. Escolhemos um para cada conjunto de discretização. Para o primeiro, basta que a parte decimal da densidade $\Delta \rho$, seja menor que 0.001 (ver figura 5.1(a)) e para o segundo basta que esta seja menor que 0.0001 (figura 5.1(b)).

\footnotetext{
${ }^{1}$ Em nosso código fixamos o valor de $U$ a 23.7 e portanto $J$ varia de 0 a 3 e $\mu$ de 1 a um múltiplo de 23.7 .
} 

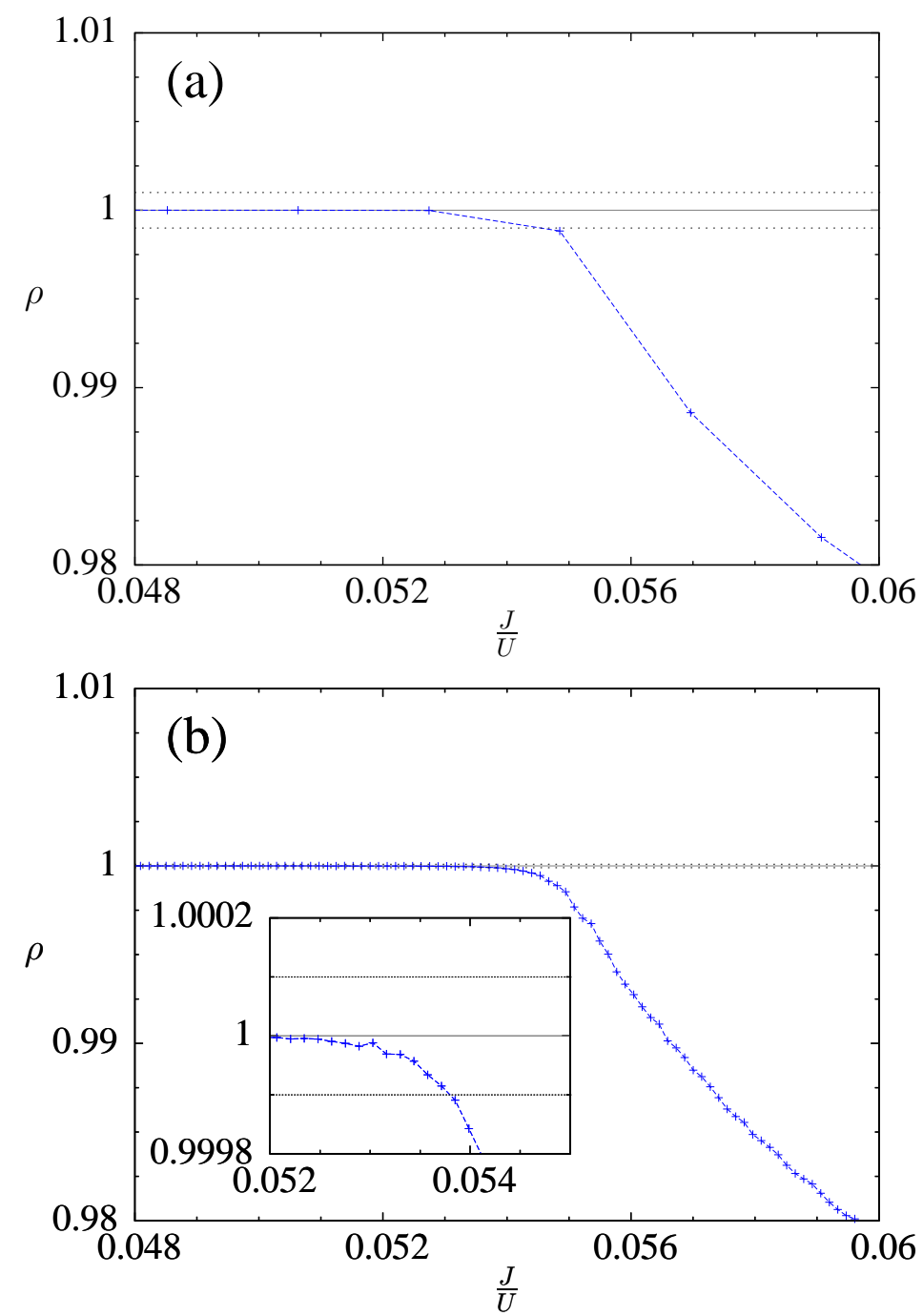

Figura 5.1: Densidade por sítio $\rho$ em função da relação $J / U$ para diferentes conjuntos de discretização de $J / U$, sendo que $\mu / U=0.295$ nas duas figuras. Em (a), a discretização de $J / U$ é 0.00211. Para definir a fronteira da transição é suficiente que $\Delta \rho<0.001$. Já em (b), a discretização de $J / U$ é 0.000132 e para definir a fronteira da transição é suficiente que $\Delta \rho<0.0001$ como indicado na ampliação. Em ambas as figuras, a linha horizontal sólida indica a densidade $\rho=1$ e as pontilhadas indicam quando $\rho=1 \pm \Delta \rho$, com $\Delta \rho$ delimitando quando a densidade por sítio é ainda considerada inteira. 


\subsubsection{Estudo da temperatura}

Diferente da aproximação de campo médio que utilizamos em nosso estudo preliminar, em que $T=0$, o algoritmo Worm depende da temperatura. A transição de fase na qual estamos interessados em estudar é puramente quântica à temperatura zero. Com uma temperatura finita, as flutuações térmicas que surgem tendem a destruir as fases isolante e superfluida nesse sistema [31]. Porém, a temperaturas suficientemente baixas, as fases previstas pelo modelo de $\mathrm{BH}$ persistem e conseguimos obter um diagrama de fases próximo do obtido à zero absoluto. Utilizaremos o gráfico feito com a teoria de campo médio (figura 3.4) como referência para a construção do diagrama que faremos com o Worm.

Entretanto, nesse caso temos que mudar a representação do diagrama. Anteriormente, ao definir as fases do sistema pelos valores relativos de $\mu, J$ e $U$, obtivemos um diagrama geral no sentido discutido no capítulo 3. Porém, como agora estamos considerando um sistema com uma temperatura finita, para garantir essa propriedade do diagrama de fases, precisamos encontrar alguma maneira de escalonar a temperatura. No QMC o estado fundamental do sistema é encontrado através da função de partição $Z$ e ao escalonar a hamiltoniana do sistema (como feito na equação (3.11)), para manter a adimensionalidade de $Z$, também temos que escalonar a temperatura de modo que $Z=\operatorname{Tr}\left[e^{-\beta H}\right]=\operatorname{Tr}\left[e^{-\frac{1}{(T / U)}(H / U)}\right]$. Assim, teremos que o diagrama de fases à temperatura finita definido pelas relações $\mu / U, J / U$ e $T / U$ é geral.

Nos experimentos atuais com átomos frios em redes óticas não se consegue atingir um sistema com temperaturas baixas o suficiente para que possamos considerá-lo no estado fundamental. Isso acontece porque ao se armadilhar o gás de bósons condensado na rede ótica o sistema ganha energia e, com isso, correções devido a temperatura se fazem necessárias. Um estudo recente dos efeitos da temperatura no diagrama de fases do modelo de Bose-Hubbard 2D pode ser encontrado em [31]. Nesta referência é identificada uma fase intermediária que surge com o aumento da temperatura denominada fase normal $(\mathrm{N})$, e é definida como uma fase incomensurável mas que não possui uma fração de superfluido (ver figura 5.2). À medida que a temperatura aumenta, esta fase normal entre as fases superfluida e isolante aumenta. 


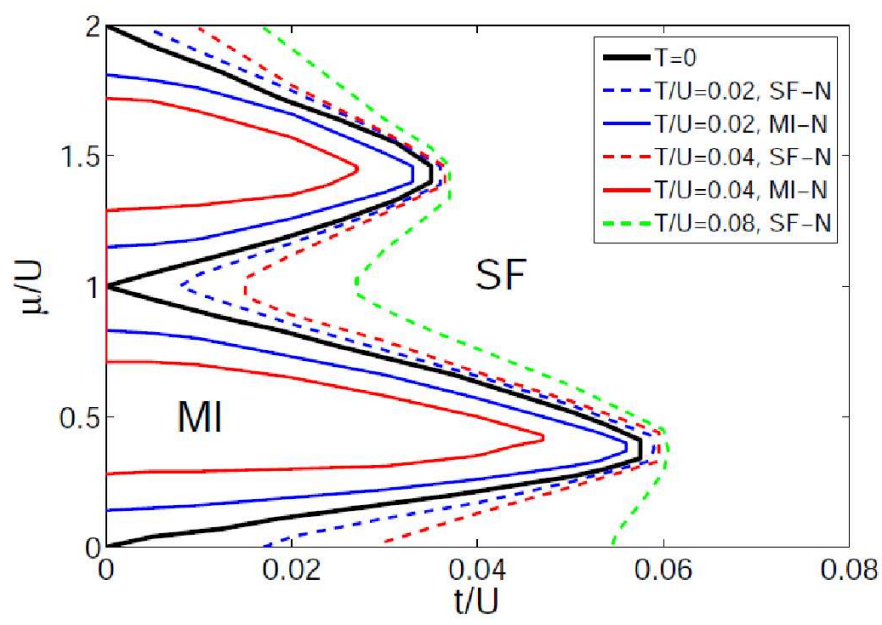

Figura 5.2: Análise da influência da temperatura no diagrama de fases para o modelo de $\mathrm{BH}$ homogêneo 2D. Aumentando $T / U$ uma região com fase normal $(\mathrm{N})$ aparece entre o MI e SF. Temos duas fronteiras de transição, uma delimitando as fases SF e N e outra as fases N e MI. (Figura extraída da referência [31].)

A figura 5.3 apresenta quatro diagramas de fases construídos com o método de Monte Carlo Quântico a diferentes temperaturas. Vemos um estreitamento dos lobos de Mott à medida que a temperatura aumenta. Este encolhimento indica o surgimento de uma fase intermediária às fases SF e MI, o que está de acordo com a referência anteriormente estudada [31]. Porém, por estar fora de nossos propósitos, não analisaremos outros observáveis que poderiam nos trazer informações de alguma outra fase que pudesse surgir com o aumento da temperatura.

Escolhemos $T / U=0.003$ para o estudo, já que o diagrama de fases com essa temperatura se mostra qualitativamente próximo do diagrama da teoria de campo médio e ao diminuirmos mais a temperatura pouca diferença se nota. 


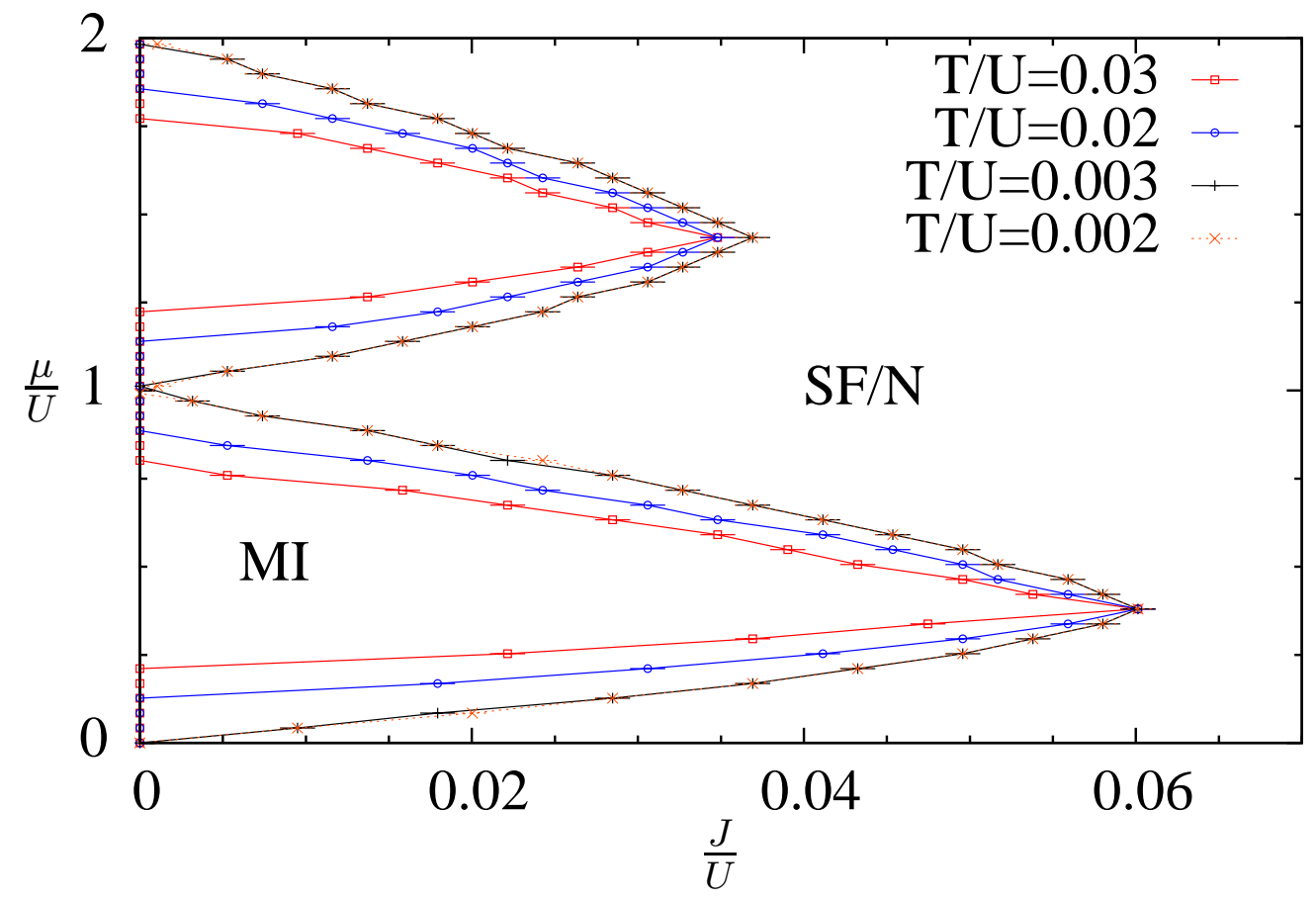

Figura 5.3: Diagrama de fases do modelo de BH para quatro temperaturas diferentes. A simulação foi feita com um tamanho linear da rede $L$ igual a 16, em que efeitos de tamanho da grade não afetam as conclusões. Nesta análise é suficiente o conjunto de discretização mais grosseiro e que acarreta em uma barra de erro no ponto da transição igual a 0.001. Fica claro nesta figura um encolhimento dos lobos de Mott à medida que a temperatura do sistema aumenta. Como não delimitamos a fase normal (N), indicamos a região que não é MI por $\mathrm{SF} / \mathrm{N}$. Os diagramas das duas últimas temperaturas mais baixas estão praticamente sobrepostos, sendo assim escolhemos a temperatura 0.003 para o estudo. 


\subsubsection{Estudo da grade}

Com um estudo numérico temos o intuito de simular exatamente o modelo ou o sistema real estudado, fazendo-se necessário uma grade infinita no primeiro caso e no segundo, uma grade com $L \sim 10^{3}$ (já que usualmente temos um número de átomos da ordem de $10^{5}$ [16]). Porém, o tempo computacional que essa simulação exige é impraticável e por isso temos que encontrar maneiras de contornar esse problema.

Numa grade finita, efeitos de borda são inevitáveis já que os sítios que estão no contorno da rede têm um número menor de vizinhos do que os sítios no interior desta. Mesmo num sistema real esses efeitos existem, sendo no entanto bem menores já que neste caso a fração de partículas que está na borda da rede ótica é menor do que a fração de partículas na borda do sistema simulado. A maneira de minimizar os efeitos de borda é utilizar condições periódicas de contorno, garantindo assim que todos os sítios tenham o mesmo número de vizinhos.

Porém, isto não garante que um sistema finito vai se comportar da mesma forma que um sistema infinito. Portanto, também se faz necessário avaliar diretamente os efeitos do tamanho da grade variando seu tamanho e, ao extrapolar para uma rede infinita, obtemos o comportamento de um sistema muito grande.

Fizemos simulações para diferentes tamanhos lineares da rede, a saber $L=16,24,32$ e 40, os resultados estão apresentados na figura 5.4. Não foi observado nenhum efeito significativo devido ao tamanho da rede para valores de $J / U$ menores que 0.05 . Na figura 5.4 (b), temos uma ampliação mais detalhada da região mais afetada. Concluímos que é suficiente para o nosso estudo a escolha da grade $L=24$, já que, como podemos observar em (b), não há melhorias significativas na definição da fronteira de transição com uma grade maior. É importante observar que se utilizarmos um conjunto de discretização menos preciso, é suficiente uma grade com $L=16$ já que as perdas na definição da fronteira devido à baixa discretização serão maiores. 

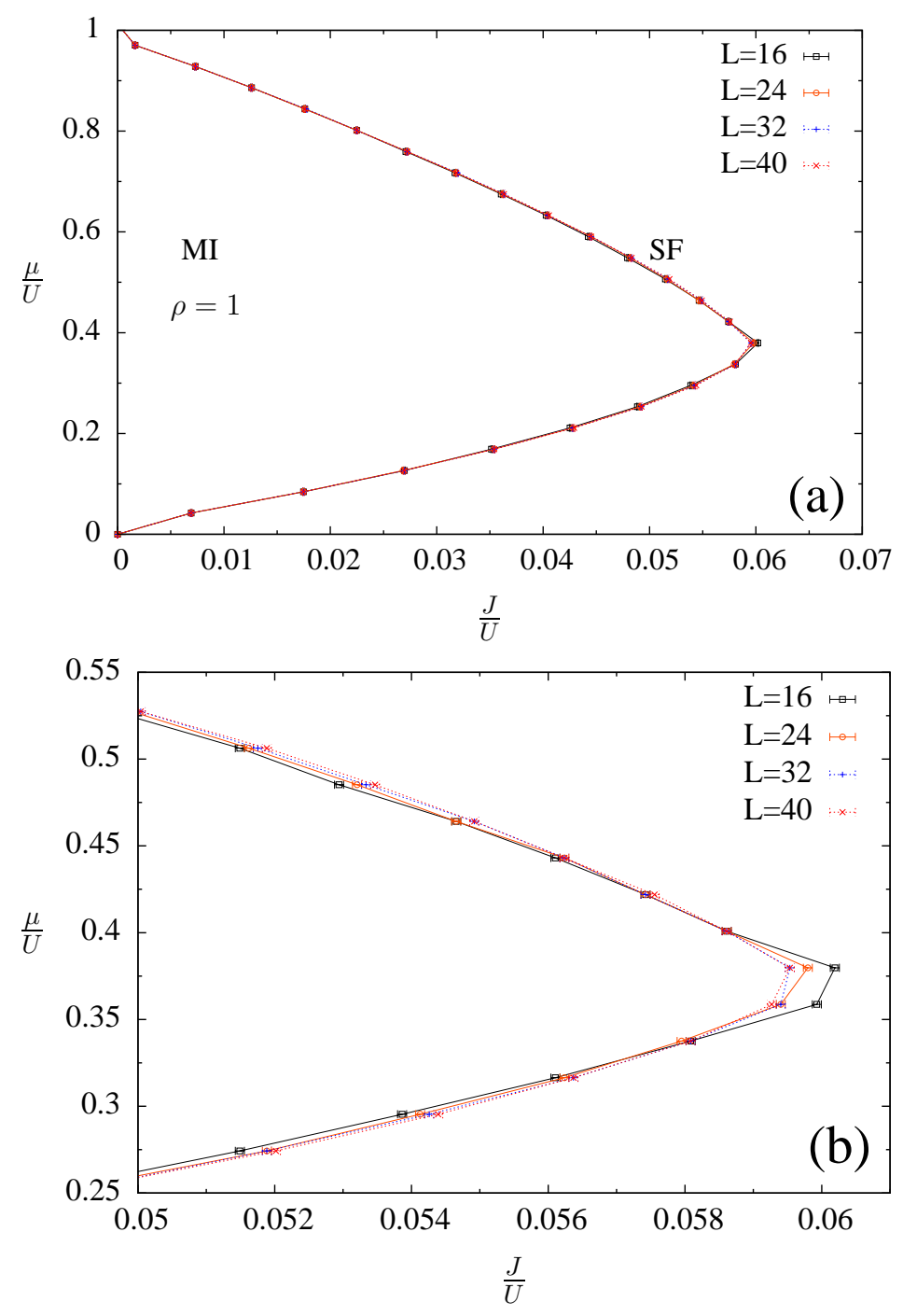

Figura 5.4: Estudo dos efeitos do tamanho finito da rede no diagrama de fases do modelo de BH. (a) Diagrama de fases para diferentes tamanhos lineares da rede, $L=16,24,32$ e 40 . Vemos que as linhas estão praticamente superpostas. (b) Ampliação (mais detalhada) da região onde efeitos relacionados ao tamanho da grade são mais relevantes. 


\subsection{Análise preliminar: comparação qualitativa com a teoria de campo médio}

Nesta seção faremos uma comparação qualitativa entre as duas abordagens que foram utilizadas para estudar o modelo de Bose-Hubbard: a aproximação de campo médio e a simulação do modelo utilizando o algoritmo Worm. A figura 5.5 apresenta dois diagramas de fases do sistema, um construído utilizando o algoritmo Worm e o outro é a figura 3.4 obtida com a teoria de campo médio. Na construção do diagrama de fases com o Worm, utilizamos o conjunto menos preciso de discretização dos parâmetros que é suficiente para fazermos uma análise qualitativa.

Como já falamos no capítulo 3, o ponto mais extremo do primeiro lobo de Mott é conhecido como o ponto crítico da transição $P_{c}$ e a região ao seu redor de região crítica. Na figura indicamos esses pontos em ambos os diagramas. A importância de $P_{c}$ ficará mais clara depois. Novamente, o utilizaremos apenas como um critério que indicará um aspecto geométrico dos lobos. Na seção seguinte, faremos uma análise quantitativa do primeiro lobo, detalhando-o e também definiremos melhor a região crítica.

O diagrama gerado com o método de QMC tem a forma prevista no estudo de campo médio feito anteriormente, mas os extremos do lobos de Mott são mais alongados não coincidindo, no caso do primeiro lobo, em uma região de $J / U$ que vai de 0.03 a 0.06 . Portanto, a aproximação de CM funciona melhor no limite em que $J / U$ é pequeno. Podemos atribuir essa diferença aos termos cruzados desprezados na aproximação de CM feita. O ponto crítico obtido com a teoria de campo médio, $P_{c}^{C M}$, do lobo com fator de preenchimento $\rho=1$ está deslocado aproximadamente $30 \%$ abaixo em $J / U$ e $8 \%$ acima em $\mu / U$ em relação ao obtido com Worm, $P_{c}^{W o r m}$. 


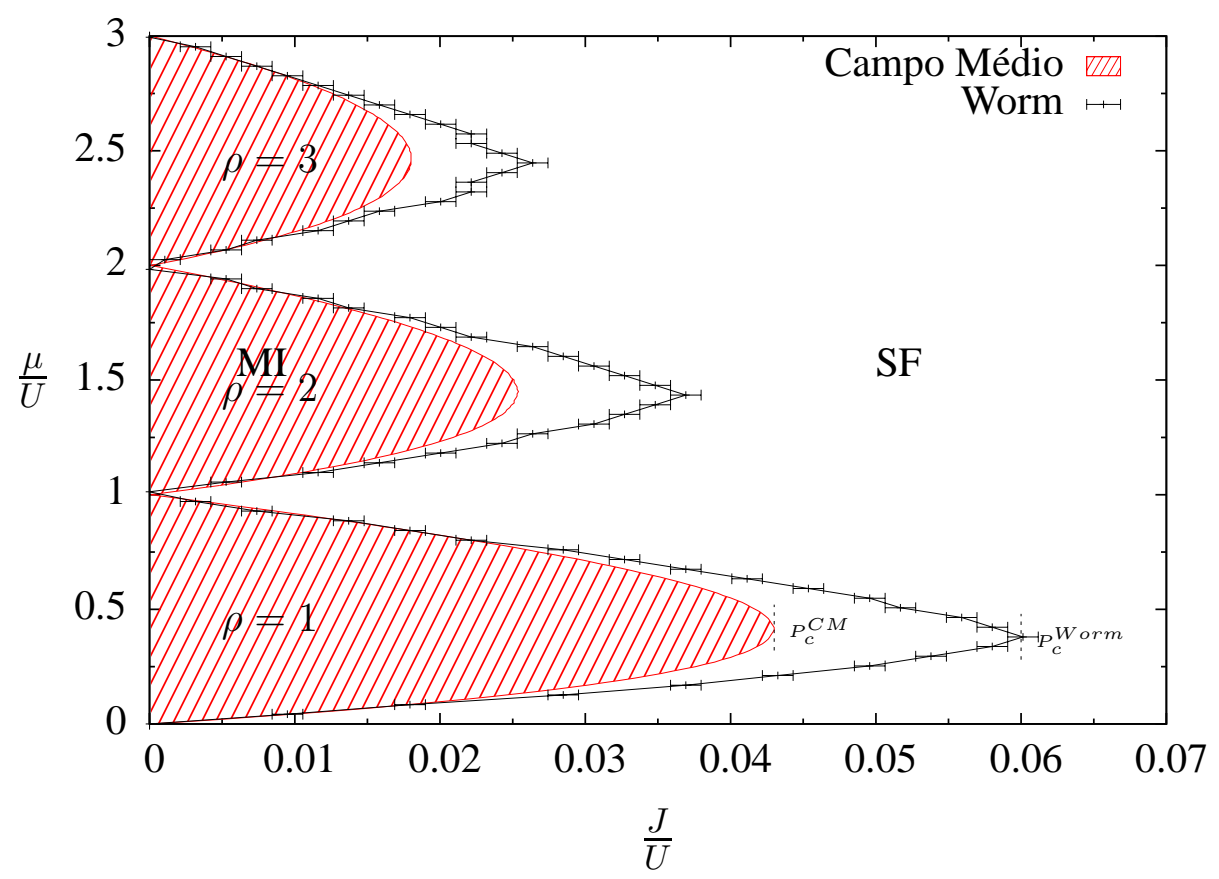

Figura 5.5: Diagrama de fases do modelo de BH homogêneo 2D construído utilizando o algoritmo Worm (fundo transparente) e a aproximação de campo médio (fundo hachurado). O tamanho linear da grade usada na simulação com QMC é $L=16$ e a temperatura $T / U=0.003$, a barra de erro dos ponto de transição é igual a 0.001. Os pontos críticos para o primeiro lobo de cada gráfico estão assinalados e seus valores são: $P_{c}^{C M}=$ $(0.0430 \pm 0.0005,0.4135 \pm 0.0003)$ e $P_{c}^{W o r m}=(0.060 \pm 0.001,0.38 \pm 0.02)$. 


\subsection{Encontrando o ponto crítico}

A importância do primeiro lobo do diagrama está no fato de que as experiências que realizam o modelo de Bose-Hubbard usualmente são feitas com densidades baixas e a fase Mott que surge quando o sistema sofre a transição tem o fator de preenchimento $\rho=1[7,16]$. Na figura 5.6, temos o detalhamento do lobo com densidade por sítio igual a $\rho=1$, que foi simulado em uma grade com $L=24$ e com a fronteira de transição entre as fases SF-MI mais definida. A ampliação, figura 5.6(a), é a região crítica com um número maior de pontos delimitando a fronteira de transição. Podemos ver um prolongamento do extremo da curva, passando a impressão de uma imprecisão na definição do ponto crítico deste lobo.

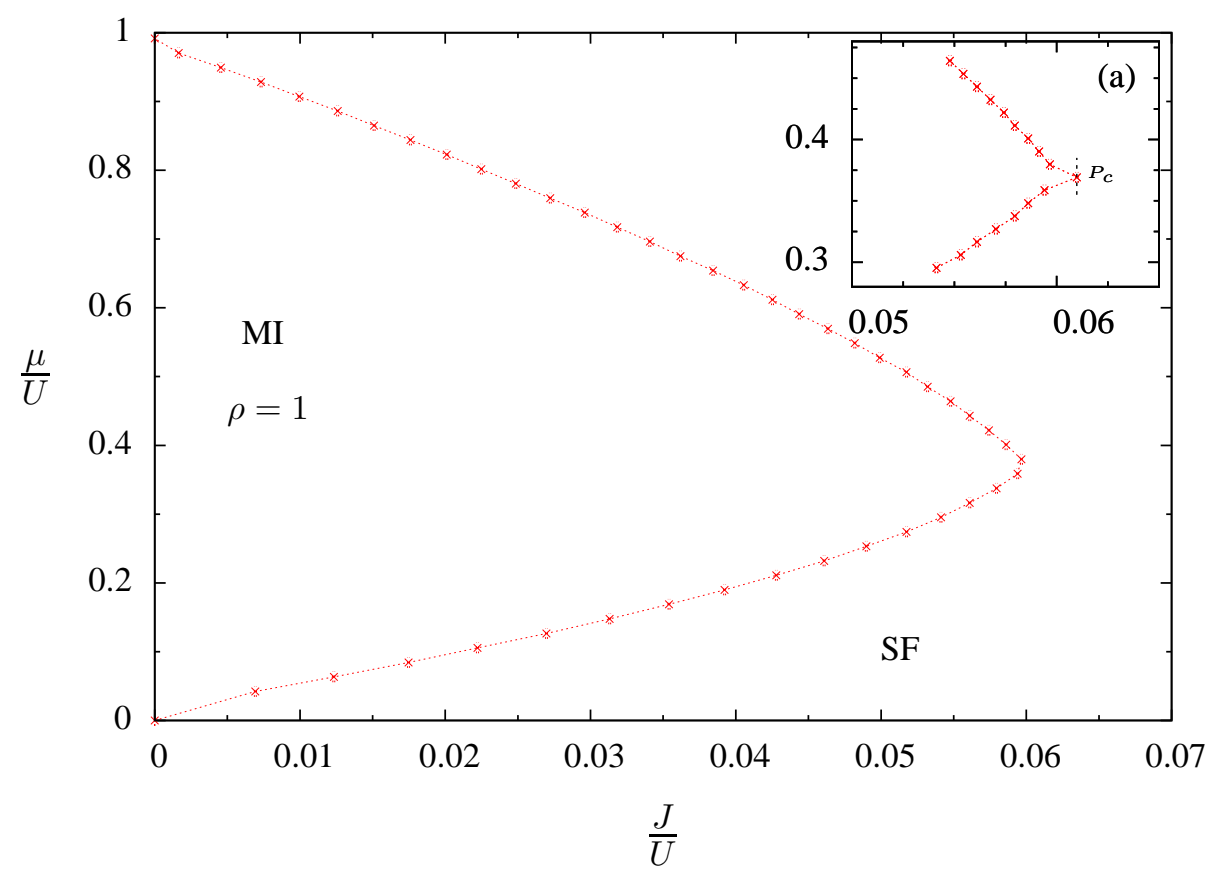

Figura 5.6: Diagrama de fases do lobo de Mott com fator de preenchimento $\rho=1$. Na construção da figura, usamos o conjunto mais preciso de discretização, $L=24$ e $T / U=0.003$. Em (a) vemos a região crítica ampliada, sendo que aumentamos a discretização de $\mu / U$. Note que há uma indefinição do extremo do lobo, mas escolhemos $P_{c}^{\text {Worm }}=$ $(0.06098 \pm 0.00007,0.37 \pm 0.01)$. 
Para nos certificar de que esse desvio encontrado na região crítica não é produzido por algum erro numérico, verificamos o comportamento do observável que define a fronteira da transição entre as fases no extremo do lobo com ambas abordagens utilizadas ao longo deste trabalho. Na figura 5.7 temos a densidade em função da relação $J / U$ para três valores diferentes do potencial químico no extremo do lobo. Na figura 5.7(a), construída com o Worm, verificamos que o sistema com o potencial químico 0.37 permanece na fase Mott até um valor maior de $J / U$ do que os outros com diferentes $\mu / U$. O mesmo comportamento foi verificado na figura 5.7(b), construída com a aproximação de campo médio indicando que este é inerente ao sistema físico e não um problema numérico.
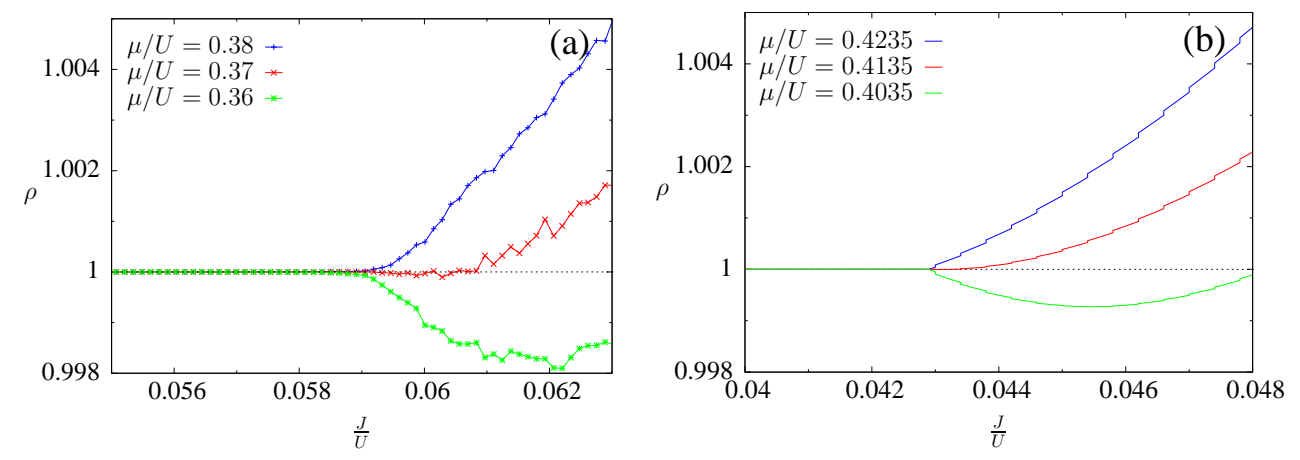

Figura 5.7: Densidade por sítio em função de $J / U$, para três pontos do extremo do lobo com um valor fixo de $\mu / U$ igual a $0.36,0.37$ e 0.38 , obtido com o Worm (fig. (a)) e para os pontos com $\mu / U$ constante e igual a 0.4035 , 0.4135 e 0.4235 obtido com a aproximação de CM (fig. (b)). Em ambos os casos verificamos um prolongamento do ponto em que a densidade deixa de ser inteira no valor $\mu / U$ intermediário.

Na literatura encontramos que no ponto crítico ocorre uma transição de fase especial a densidade inteira constante. Ela foi descrita pela primeira vez por Fisher et al. [9] e classificada como sendo da mesma classe de universalidade do modelo XY clássico em $(d+1)$-dimensões, em que $d$ é a dimensão da rede ótica.

Em boa aproximação podemos dizer que experimentalmente o número de partículas é fixo. Então, a única maneira de uma fração do sistema na fase SF entrar no domínio da fase Mott é pelo ponto crítico, já que a transição é conduzida a densidade constante. Como discutiremos adiante, experimentalmente não se consegue encontrar o ponto em que esta transição 
ocorre com precisão. No entanto, há cálculos numéricos muito precisos que são importantes por servirem como guias para os experimentais colocarem o modelo à prova.

Não conseguimos remover a arbitrariedade existente na determinação do ponto crítico e optamos por adotar o ponto mais extremo em que a densidade ainda é inteira como o seu valor, já que qualquer outra escolha baseada nos critérios adotados aqui seria igualmente imprecisa. Então, o valor do ponto crítico determinado pelas nossas simulações é: $P_{c}^{W o r m}=(J / U, \mu / U)_{c}=$ $(0.06098 \pm 0.00007,0.37 \pm 0.01)$. Um sistema correlacionado requer uma estimativa dos erros estatísticos mais elaborada, caso contrário estes serão fatalmente subestimados [15]. Por isso, consideramos apenas os erros devido à discretização escolhida.

\subsubsection{Comparação com a literatura}

A referência [32] apresenta o cálculo mais preciso do ponto crítico da transição SF-MI que podemos encontrar na literatura para o lobo com preenchimento $\rho=1$ no caso 2D homogêneo, e foi estimado utilizando o mesmo algoritmo, o Worm. Para obter a localização deste ponto com precisão, os autores utilizaram técnicas de escalonamento do tamanho finito [33] que determinam o ponto crítico no limite em que o sistema é infinito. Encontraram $(J / U)_{c}=0.05974 \pm 0.00003$ para o ponto crítico. O valor de $(J / U)_{c}=0.06098 \pm 0.00007$ encontrado por nós está superestimado em aproximadamente $2 \%$ em relação ao encontrado pelos autores do artigo [32]. Veja que mesmo sem uma análise mais precisa da influência do tamanho do sistema, nosso resultado obtém um valor razoavelmente próximo deste valor de refência. Uma outra estimativa teórica que usa uma expansão de acoplamento forte fornece o valor de $(J / U)_{c}=0.057 \pm 0.007$ [23], subestimado em apenas $6.5 \%$ em relação ao valor encontrado aqui. Lembrando que o valor crítico na transição encontrado no capítulo 3 na aproximação de campo médio é subestimado em torno de $30 \%$ em relação ao que encontramos.

\subsubsection{Comparação com os experimentos atuais}

Nos experimentos atuais, o gás de bósons é primeiramente confinado em uma armadilha harmônica e resfriado até a condensação de Bose-Einstein. A rede ótica é então sobreposta a este sistema aumentando-se gradualmente a intensidade dos lasers que a formam, procurando fazer esse processo ser lento o suficiente para manter o sistema em estados de baixas energias mas rápido o suficiente para que tal influência externa seja pequena [34]. Apesar 
do sistema inicial ser preparado a temperaturas baixas, após carregar a rede ótica temos um aumento da temperatura [31, 34]. Como discutido anteriormente, se esta temperatura for grande o suficiente ela pode esconder a assinatura da transição de fase substituindo-a por uma transição térmica.

Outra dificuldade experimental é que para evitar a depleção do condensado é necessário manter a armadilha harmônica durante o experimento. Esta armadilha encurva a rede ótica (ver figura 5.8), o que introduz uma diferença de energia entre os sítios e faz com que se perca a invariância translacional discreta da rede e consequentemente ficam invalidadas as propriedades de periodicidade estudadas na seção 2.1. Neste caso, usualmente se considera um termo a mais na hamiltoniana do sistema representando a influência desta armadilha, e.g. $\sum_{i} V r_{i}^{2} n_{i}$ no caso de uma armadilha parabólica, com $V$ a curvatura desta e $r_{i}$ a distância do sítio em relação ao centro da armadilha. O que equivale a aproximar o efeito da armadilha por uma variação local do potencial químico em cada sítio e que pode ser descrita por um potencial químico efetivo, $\mu_{i}^{e f}=\mu-V r_{i}^{2}$, tornando o condensado heterogêneo, ou seja, teremos ambas as fases SF e MI coexistindo na rede $[5,35]$.

Um entendimento qualitativo do que acontece nesse sistema pode ser obtido pelo diagrama de fases do sistema homogêneo. Como o efeito da armadilha é introduzir ao longo da rede diferentes potenciais químicos podemos representar a fase em que o sistema se encontra por uma linha sólida finita neste diagrama, sendo delimitada pelos potenciais químicos efetivos do centro e do extremo da armadilha. Ao variar a razão entre o termo de tunelamento e a interação intra-sítio esta linha se deslocará. Então, com um valor de $J / U$ grande o suficiente podemos ter o sistema todo inicialmente na fase SF. À medida que diminuímos este parâmetro, uma região com densidade inteira, isto é, na fase Mott, se forma no centro e no extremo da armadilha. Assim, um anel de SF cercará o platô isolante que se formará no centro da armadilha.

Por isso, para um entendimento completo dos resultados experimentais é importante um estudo mais detalhado dos efeitos da temperatura [31, 34] e da armadilha harmônica confinante $[31,35]$. Um estudo numérico dos efeitos da armadilha harmônica foi feito na referência [35]. Estes autores estimaram o ponto transição mais extremo do primeiro lobo no caso homogêneo encontrando $(\mu / U, U / J)_{c}=(0.37,16.25 \pm 0.1)$ (ou seja, $\left.J / U=0.06154\right)$. E para um sistema com uma armadilha parabólica de curvatura $V / U=0.002$ centralizada em $\mu / U=0.37$, encontraram esse ponto em $U / J \approx 16.7$ (ou seja, $J / U=0.0599$ ). Veja que o ponto crítico no caso homogêneo é aproximadamente $3 \%$ menor do que no caso inomogêneo, o que mostra que podemos 


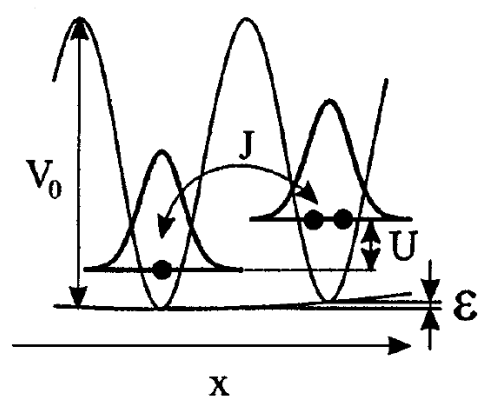

Figura 5.8: Curvatura na rede ótica causada pela armadilha harmônica, o que introduziu uma diferença de energia $\varepsilon$ entre os dois sítios dessa figura. (Figura extraída da referência [8].)

comparar uma experiência em que a armadilha harmônica utilizada tem uma curvatura pequena com os nossos resultados.

Em geral, os experimentos atuais que estudam a transição SF-MI são realizados com um número de ocupação por sítio baixo, da ordem de 1-3 bósons. A transição é induzida variando a profundidade do poço, já que desta forma alteramos a relação $J / U$. Usualmente se estuda a distribuição de momento do condensado, medindo o padrão de interferência do gás após o desligamento completo das armadilhas. Consegue-se imagens bem definidas da fase puramente Mott (não há padrão de interferência) e da puramente SF (padrão de interferência bem definido), porém, devido a coexistência de fases na armadilha, é difícil determinar o ponto da transição com precisão e se faz necessário o uso de outras técnicas para tentar identificar melhor o início da transição.

A primeira realização experimental da transição de fase quântica SFMI foi feita em 2002 por Greiner et al. [7] em um condensado atômico de ${ }^{87} \mathrm{Rb}$ carregado em uma rede ótica tridimensional. Estudaram o espectro de excitação e o padrão de interferência do gás para diferentes profundidades do potencial da rede $V_{o}$ e obtiveram resultados que indicam que a transição experimental ocorre entre os valores $V_{0}=12-13 E_{r}$, onde $E_{r}$ é a energia de recuo, com $E_{r}=\hbar^{2} k^{2} / 2 m$. Utilizando os parâmetros do experimento a relação entre $U$ e $J$ para uma profundidade de poço $13 E_{r}$ é $U / J \approx 36$ (i.e., $J / U \approx 0.028$ ). Apenas em 2007 um experimento estuda essa transição em uma rede bidimensional, verificando que o seu ponto crítico acontece próximo do previsto teoricamente, $J / U \approx 0.06$ [16]. Esse experi- 


\begin{tabular}{|l|c|c|}
\hline & $(J / U)_{c}$ & $(\mu / U)_{c}$ \\
\hline $\mathrm{CM}$ & $0.0430 \pm 0.0005$ & $0.4135 \pm 0.0003$ \\
\hline Worm & $0.06098 \pm 0.00007$ & $0.37 \pm 0.01$ \\
\hline Ref. $[32]$ & $0.05974 \pm 0.00003$ & $\approx 0.37$ \\
\hline Ref. $[23]$ & $0.057 \pm 0.007$ & $0.388 \pm 0.05$ \\
\hline Ref. $[16]^{\dagger}$ & $\approx 0.06$ & - \\
\hline
\end{tabular}

${ }^{\dagger}$ Sistema armadilhado.

Tabela 5.1: Sumário das estimativas do valor do ponto crítico obtidos neste trabalho e na literatura disponível.

mento também foi realizado utilizando um gás de ${ }^{87} \mathrm{Rb}$ com uma densidade de aproximadamente 1 átomo por sítio. Com essa experiência confirmamos que o valor aqui encontrado para o ponto crítico está dentro da região de transição observada experimentalmente. Todos estes resultados estão resumidos na tabela 5.1 . 


\section{Capítulo 6}

\section{Conclusão}

Estudamos a transição de fase que ocorre em sistemas de bósons ultrafrios armadilhados em uma rede ótica, conhecida como transição de Mott. Esta transição é bem descrita pelo modelo de Bose-Hubbard e corresponde à mudança do sistema de uma fase superfluida para uma fase isolante de Mott. Vimos que podemos induzí-la pela variação da profundidade do potencial dos sítios que compõe a rede já que esta muda a relação entre o termo de tunelamento e a interação entre os átomos.

Nos restringimos ao caso 2D homogêneo, com rede quadrada, e consideramos apenas as interações entre átomos de um mesmo sítio e o tunelamento de partículas entre sítios vizinhos. Encontramos o diagrama de fases da transição de Mott a partir de uma aproximação de campo médio e também utilizando o algoritmo Worm, que é um Monte Carlo Quântico. Os diagramas obtidos são gerais no sentido que dependem apenas de valores relativos de $T, J, U$ e $\mu$.

O estudo feito com uma aproximação de campo médio nos ajudou a entender a dinâmica do sistema. Também conseguimos reproduzir o diagrama de fases já obtido na literatura e estimar o ponto crítico da transição, o ponto mais extremo da fronteira entre as fases SF-MI do plano $\mu / U \times J / U$, em que foi obtido um valor muito próximo do encontrado em outros estudos $[12,13]$.

O Worm se mostrou adequado aos nossos propósitos. Como vimos no final do capítulo 4, por causa das atualizações locais, ele é eficiente em criar configurações topologicamente diferentes e que são separadas por uma barreira de energia. Porém, ao contrário do esperado em algoritmos com atualizações locais, não é afetado pelo critical slowing down já que colhe estatísticas para a função de Green facilmente. Além disso, o espaço de con- 
figurações do Worm é maior do que outros algoritmos de QMC conhecidos, já que inclui caminhos abertos e fechados. Isto nos permite coletar estatísticas mais eficientemente e estimar outros observáveis a partir da função de Green, tais como a fração de superfluido, a fração do condensado e a distribuição do momento. Entretanto, vale a ressalva de que o algoritmo Worm não é capaz de simular a evolução temporal do sistema, sendo restrito ao estado fundamental.

Tendo em vista que o algoritmo Worm depende da temperatura, fizemos um estudo das influências desta no diagrama. Pudemos observar o encolhimento da fase Mott à medida que a temperatura aumenta. Esse resultado concorda com o que foi apresentado em [31], onde foi feito um estudo da influência da temperatura em um sistema como o aqui analisado, prevendo o surgimento de uma fase denominada normal entre as fases superfluida e isolante. Vale ressaltar que esse é um dos fatores que contribuem para uma imprecisão da determinação do ponto crítico da transição experimentalmente.

Também fizemos uma análise das influências do tamanho finito da grade na simulação. Mesmo sem extrapolar para o limite em que o sistema é infinito, conseguimos obter uma boa estimativa para o ponto crítico, com um valor comparativamente muito próximo ao que foi encontrado em dois outros estudos, um numérico [32] e outro teórico [23]. Superestimamos o valor encontrado na primeira referência em $2 \%$ e o valor encontrado na segunda está subestimado em relação ao nosso em $6.5 \%$, valores que estão próximos da estimativa medida experimentalmente [16].

O diagrama de fases obtido com a aproximação de campo médio se mostrou qualitativamente correto, reproduzindo bem as fronteiras da transição do diagrama obtido com o algoritmo Worm quando a interação é dominante sobre a intensidade de tunelamento. Porém, subestima a fronteira numa região mais próxima da região crítica. O ponto crítico obtido com a teoria de campo médio está deslocado aproximadamente $30 \%$ abaixo em $J / U$ e $8 \%$ acima em $\mu / U$ em relação ao obtido com o algoritmo Worm.

Destacamos agora algumas perspectivas de continuação do trabalho. Uma delas é a aplicação do algoritmo Worm em sistemas com pequenas modificações nas quais o modelo de Bose-Hubbard pode ainda ser aplicado, tal como a modificação da rede para uma forma hexagonal. Outra é a sua utilização no estudo de sistemas com multicamadas de redes óticas interagindo, preenchidas com um gás de bóson ou alguma mistura. Além disso, no estudo que foi apresentado não utilizamos todo o espaço de configurações que pode ser explorado pelo algoritmo Worm. O único observável utilizado é estimado com estatísticas coletadas pelo espaço de configurações CF. Porém, 
como já dissemos, há outros observáveis que são calculados a partir das configurações $\mathrm{CF}_{g}$ que podem ser utilizados para obter mais informação do modelo estudado. 


\section{Apêndice A}

\section{Segunda quantização}

Para descrever um sistema de muitos corpos é conveniente utilizar o formalismo da segunda quantização, onde passamos a atuar em um espaço de Hilbert denominado espaço de Fock. Baseados na referência [21] revisaremos as definições mais básicas e algumas relações que são usadas ao longo desta tese, particularizando ao caso de bósons sem spin. Outras referências que tratam especificamente do problema de muitos corpos e que introduzem o formalismo da segunda quantização são [36, 37].

Introduzindo os operadores de campo bosônicos, $\Psi(\mathbf{r})$ e $\Psi^{\dagger}(\mathbf{r})$, caracterizados pelas relações de comutação

$$
\begin{aligned}
{\left[\Psi(\mathbf{r}), \Psi^{\dagger}\left(\mathbf{r}^{\prime}\right)\right] } & =\delta^{3}\left(\mathbf{r}-\mathbf{r}^{\prime}\right) \\
{\left[\Psi(\mathbf{r}), \Psi\left(\mathbf{r}^{\prime}\right)\right] } & =0,
\end{aligned}
$$

em que $\mathbf{r}$ se refere a posição no espaço e não deve ser confundido com a variável dinâmica de posição da partícula usada na formulação usual. Interpretamos o operador $\Psi^{\dagger}(\mathbf{r})$ como o operador de criação de uma partícula no ponto $\mathbf{r}$, isto é,

$$
\Psi^{\dagger}(\mathbf{r})|0\rangle=|\mathbf{r}\rangle,
$$

sendo $|0\rangle$ definido como o estado de vácuo, no qual não há partículas. De maneira análoga, o hermitiano conjugado desse operador é interpretado como o operador de aniquilação de uma partícula na posição em que está definido.

É conveniente expandir a dependência de $\mathbf{r}$ desses operadores em termos 
de um conjunto completo de funções $\Phi_{j}(\mathbf{r})$ ortonormais,

$$
\begin{aligned}
\Psi(\mathbf{r}) & =\sum_{j} \Phi_{j}(\mathbf{r}) b_{j} \\
\Psi^{\dagger}(\mathbf{r}) & =\sum_{j} \Phi_{j}^{*}(\mathbf{r}) b_{j}^{\dagger} .
\end{aligned}
$$

Os coeficientes $b_{j}$ e $b_{j}^{\dagger}$ são operadores conhecidos como operadores de aniquilação e criação, respectivamente, e podem ser expressos em termos de $\Psi(\mathbf{r})$ e $\Psi^{\dagger}(\mathbf{r})$ utilizando a ortonormalidade das funções $\Phi_{j}(\mathbf{r})$. É fácil demonstrar que também obedecem as seguintes relações de comutação

$$
\begin{aligned}
& {\left[b_{i}, b_{j}^{\dagger}\right]=\delta_{i j}} \\
& {\left[b_{i}, b_{j}\right]=0 .}
\end{aligned}
$$

Os estados de Fock, rotulados pelos números de ocupação $n_{i}$ no estado $i$, são definidos por

$$
\left|n_{1}, n_{2}, \ldots, n_{i}, \ldots\right\rangle=\prod_{i} \frac{\left(b_{i}^{\dagger}\right)^{n_{i}}}{\sqrt{n_{i} !}}|0\rangle,
$$

sendo os números de ocupação restritos ao número total de partículas, $\sum_{\text {é }} n_{i}=N$. A atuação dos operadores até então definidos nesse estado

$$
\begin{aligned}
b_{i}\left|n_{1}, \ldots, n_{i}, \ldots\right\rangle & =\sqrt{n_{i}}\left|n_{1}, \ldots, n_{i}-1, \ldots\right\rangle \\
b_{i}^{\dagger}\left|n_{1}, \ldots, n_{i}, \ldots\right\rangle & =\sqrt{n_{i}+1}\left|n_{1}, \ldots, n_{i}+1, \ldots\right\rangle .
\end{aligned}
$$

Note que a ação de $b_{i}^{\dagger}$ é interpretada como a criação de uma partícula no estado cuja função de onda (amplitude de probabilidade) é $\Phi_{i}(\mathbf{r})$.

Uma classe importante de operadores que é possível construir é a dos chamados operadores de número, que podem ser definidos em termos dos operadores de campo

$$
N=\int d \mathbf{r} \Psi^{\dagger}(\mathbf{r}) \Psi(\mathbf{r}),
$$

ou em termos dos operadores $b_{i}$ e $b_{i}^{\dagger}$

$$
\begin{array}{r}
N=\sum_{i} b_{i}^{\dagger} b_{i} \\
\hat{n}_{i}=b_{i}^{\dagger} b_{i},
\end{array}
$$


e sua atuação no espaço de Fock é

$$
\hat{n}_{i}\left|n_{1}, \ldots, n_{i}, \ldots\right\rangle=n_{i}\left|n_{1}, \ldots, n_{i}, \ldots\right\rangle,
$$

justificando seu nome.

Por fim, definimos também a ação de operadores de um e dois corpos $\hat{T}(\mathbf{r})$ e $\hat{T}\left(\mathbf{r}, \mathbf{r}^{\prime}\right)$, respectivamente, que nesta representação são:

$$
\begin{aligned}
\hat{T}(\mathbf{r}) & =\int d^{3} r \Psi^{\dagger}(\mathbf{r}) \hat{T}(\mathbf{r}) \Psi(\mathbf{r}) \\
\hat{T}\left(\mathbf{r}, \mathbf{r}^{\prime}\right) & =\int d^{3} r d^{3} r^{\prime} \Psi^{\dagger}(\mathbf{r}) \Psi^{\dagger}\left(\mathbf{r}^{\prime}\right) \hat{T}\left(\mathbf{r}, \mathbf{r}^{\prime}\right) \Psi\left(\mathbf{r}^{\prime}\right) \Psi(\mathbf{r}),
\end{aligned}
$$

e que podem ser colocado em termos dos operadores de criação e aniquilação. 


\section{Referências Bibliográficas}

[1] F. Dalfovo, S. Giorgini, L. P. Pitaevskii, S. Stringari, "Theory of BoseEinstein condensation in trapped gases", Rev. Mod. Phys. 71, 463 (1999).

[2] D. S. Durfee, W. Ketterle, "Experimental studies of Bose-Einstein condensation", Opt. Express 2, 299 (1998).

[3] I. Bloch, "Quantum gases in optical lattices", Physics World 17, 25 (2004).

[4] M. Lewenstein, A. Sanpera, V. Ahufinger, B. Damski, A. Sen, U. Sen, "Ultracold atomic gases in optical lattices: mimicking condensed matter physics and beyond", Adv. in Phys. 56, 243 (2007).

[5] I. Bloch, J. Dalibard, W. Zwerger, "Many-body physics with ultracold gases", Rev. Mod. Phys. 80, 885 (2008).

[6] S. Inouye, M. R. Andrews, J. Stenger, H. J. Miesner, D. M. Stamper-Kurn, W. Ketterle, "Observation of Feshbach resonances in a Bose-Einstein condensate", Nature 392, 151 (1998).

[7] M. Greiner, O. Mandel, T. Esslinger, T. W. Hansch, I. Bloch, "Quantum phase transition from a superfluid to a Mott insulator in a gas of ultracold atoms", Nature (London) 415, 39 (2002).

[8] D. Jaksch, C. Bruder, J. I. Cirac, C. W. Gardiner, P. Zoller, "Cold bosonic atoms in optical lattices", Phys. Rev. Lett. 81, 3108 (1998).

[9] M. P. A. Fisher, P. B. Weichman, G. Grinstein, D. S. Fisher, "Boson localization and the superfluid-insulator transition", Phys. Rev. B 40, 546 (1989).

[10] F. H. L. Essler, H. Frahm, F. Gohmann, A. Klumper, V. E. Korepin, "The one-dimensional Hubbard model", Cambridge (2005). 
[11] M. Imada, A. Fujimori, Y. Tokura, "Metal-insulator transitions", Rev. Mod. Phys. 70, 1039 (1998).

[12] K. Sheshadri, H. R. Krishnamurthy, R. Pandit, T. V. Ramakrishnan, "Superfluid and Insulating Phases in an Interacting-Boson Model: MeanField Theory and the RPA", Europhys. Lett. 22, 257 (1993).

[13] M. Ö. Oktel, M. Nită, B. Tanatar, "Mean-field theory for Bose-Hubbard model under a magnetic field", Phys. Rev. B 75, 045133 (2007).

[14] N. Prokof'ev, B. V. Svistunov, I. S. Tupitsyn, "Exact, complete, and universal continuous-time worldline Monte Carlo approach to the Statistics of discrete quantum systems", JETP 87, 310 (1998).

[15] Notas de aula escritas pelo grupo teórico de sólidos, líquidos e gases quânticos da Universidade de Massachusetts Amherst, http://mcwa.csi.cuny.edu/umass/lectures.html .

[16] I. B. Spielman, W. D. Phillips, J. V. Porto, "Mott-insulator transition in a two-dimensional atomic bose gas", Phys. Rev. Lett. 98, 080404 (2007).

[17] N. W. Ashcroft, N. D. Mermin, "Solid state physics", Holt, Rinehardt and Winston (1976).

[18] C. J. Pethick, H. Smith, "Bose-Einstein condensation in dilute gases", Cambridge University Press (2008).

[19] A. F. R. de Toledo Piza, Escola de verão em "Física de muitos corpos com átomos frios bosônicos e fermiônicos" (2011), http://www.fma.if.usp.br/ piza/EFT/v11.pdf .

[20] M. Greiner, Tese de Doutoramento: "Ultracold quantum gases in three-dimensional optical lattice potentials", http://greiner.physics.harvard.edu/PDF\%20Files/PhD_greiner.pdf .

[21] A. F. R. de Toledo Piza, "Mecânica quântica", Edusp (2003).

[22] J. M. Ziman, "Principles of the theory of solid", Cambridge University Press (1972).

[23] J. K. Freericks, H. Monien, "Strong-coupling expansions for the pure and disordered Bose-Hubbard model", Phys. Rev. B 53, 2691 (1996).

[24] D. van Oosten, P. van der Straten, H. T. C. Stoof, "Quantum phases in optical lattice", Phys. Rev. A 63, 053601 (2001). 
[25] W. Greiner, "Quantum mechanics: an introduction", Springer (2001).

[26] N. J. Giordano, "Computational physics", Prentice Hall (2006).

[27] J. Amundsen, introduz o gerador de números aleatórios em: http://folk.ntnu.no/joern/t3e-asm/vranmar.html .

[28] N. Prokof'ev, notas de aula apresentadas no curso "Simulations of quantum many body systems" oferecido em 2010, disponível no site: https://wiki.phys.ethz.ch/quantumsimulations/_media/lecture_101021.pdf

[29] L. D. Landau, E. M. Lifshitz, "Statistical physics" (parte 2), Pergamon Press (1969).

[30] C. Trefzger, Tese de Doutoramento: "Ultracold Dipolar Gases in Optical Lattices", http://tdx.cat/bitstream/handle/10803/6596

/TCT1de1.pdf? sequence $=1$.

[31] K. W. Mahmud, E. N. Duchon, Y. Kato, N. Kawashima, R. T. Scalettar, N. Trivedi, "Finite temperature study of bosons in a two dimensional optical lattice", e-print arXiv:1101.5726v1 .

[32] B. Capogrosso-Sansone, S. G Söyler, N. Prokof'ev, B. Svistunov, "Monte Carlo study of the two-dimensional Bose-Hubbard model", Phys. Rev. A 77, 015602 (2008).

[33] K. Binder, D. W. Heermann, "Monte Carlo simulation in statistical physics", Springer-Verlag (1992).

[34] L. Pollet, C. Kollath, K. V. Houcke, M. Troyer, "Temperature changes when adiabatically ramping up an optical lattice", New J. Phys. 10, 065001 (2008).

[35] S. Wessel, F. Alet, M. Troyer, G. G. Batrouni, "Quantum Monte Carlo simulations of confined bosonic atoms in optical lattices", Phys. Rev. A 70, 053615 (2004).

[36] A. L. Fetter, J. D. Walecka, "Quantum theory of many-particle systems", Dover (2003).

[37] J. W. Negele, H. Orland, "Quantum many-particle systems", AddisonWesley (1988). 